\title{
A Novel Excavation and Construction Method for an Extra-Long Underwater Tunnel in Soft Soils
}

\author{
Jian Wu $\mathbb{D}^{1},{ }^{1}$ Zhifang Zhou $\mathbb{D}^{1},{ }^{1}$ Wenjun Xia, ${ }^{2}$ Haixiao Wang, ${ }^{2}$ and Zhongqiang Fang ${ }^{3}$ \\ ${ }^{1}$ School of Earth Sciences and Engineering, Hohai University, Nanjing 210098, China \\ ${ }^{2}$ Construction Bureau of Traffic Engineering in Jiangsu Province, Nanjing 210001, China \\ ${ }^{3}$ China Design Group Co., Ltd., Nanjing 210014, China \\ Correspondence should be addressed to Jian Wu; wujian1994@hhu.edu.cn
}

Received 19 May 2021; Revised 17 September 2021; Accepted 29 October 2021; Published 20 November 2021

Academic Editor: Guoyang Fu

Copyright $\odot 2021$ Jian Wu et al. This is an open access article distributed under the Creative Commons Attribution License, which permits unrestricted use, distribution, and reproduction in any medium, provided the original work is properly cited.

\begin{abstract}
The cut-and-cover technique is widely used in the field of tunnel engineering owing to its simple construction technology, high working efficiency, and low cost. However, the safety of the foundation pit and the environmental impact during excavation are of great concern, especially for tunnels that pass through lakes and/or rivers. In this paper, a novel excavation and construction method is presented for the Taihu tunnel, which is the longest lake-crossing tunnel in China. In this method, a cofferdam of double-row steel sheet piles (DSSPs) was designed in order to divide the overlying excavation into several closed zones. During the construction, four zones were regarded as a unit, and different construction steps were carried out simultaneously in each zone. Therefore, an assembly line for the tunnel excavation was established to accelerate the construction speed. The most distinctive advantage of this method is that the excavation did not cut off the normal flow of the lake water and the shipping routes, with low environmental impact. To investigate the tunnel deformation during excavation, a finite element analysis combined with field monitoring data was adopted, indicating that the magnitude of the tunnel deformation was notably less than those reported from other excavation projects. Moreover, the effect of groundwater on the piles and the safety of the foundation pit was revealed using numerical modelling. This study provides a new idea for the design and construction of tunnel engineering, especially for extralong underwater tunnels in soft deposits.
\end{abstract}

\section{Introduction}

Underwater tunnels are inevitably constructed in the highway projects that cross rivers and/or lakes using the drill-and-blast, shield-bored tunnelling, and immersed tube methods [1-4]. Compared with the above methods, the cutand-cover technique may be more suitable for tunnel construction in soft soils [5-8] owing to its simple construction technology, high working efficiency, and low cost. However, the deformation behaviours and the environmental impacts caused by excavation are of great concern for both engineering safety and ecological protection.

Retaining structures, such as diaphragm walls, cement mixed piles, jet grouting columns, and bored piles, can effectively control deformation behaviour. Many studies have focused on the performance of diaphragm walls during excavation. However, few researchers have documented the deflection of bored piles caused by lateral soil movements. Ong et al. [9] examined the large deflections of bored piles as a direct result of lateral soil movements due to slope failure. Cui et al. [10] investigated the behaviour of a large-scale foundation pit supported by bored piles and inclined steel struts. Chong and Ong [11] discussed the field observations of a contiguous bored pile wall system affected by accidental groundwater drawdown. They showed that the accidental groundwater leakage led to small wall deflection. Zhou et al. [12] presented a field study on the compressive bearing capacity of a prebored grouted planted (PGP) pile and a bored pile embedded in deep soft clay. However, for foundation pits supported by various piles (i.e., bored piles, cement mixed piles, and cut-off walls), the relationship between the deflection of bored piles and the excavation depth has seldom been investigated. 
Another key factor for controlling tunnel deformations is the excavation and construction method, especially when the soil parameters are determined at the design phase. Zoned and staged construction methods, including the parallel isolation excavation method [13], the perpendicular partitioned excavation method [14], and the divided alternate excavation method [15], are commonly used in cutand-cover tunnelling. In these methods, by dividing a large pit into several small zones, the excavation can be significantly shortened, and the rigid floor slabs can be cast as early as possible. However, for an extra-long underwater tunnel with a larger excavation depth and a high unload ratio, the tunnel deformation may not be controlled with conventional construction schemes. More importantly, the normal flow of the surface water and the shipping routes are affected by these construction methods, with potentially severe environmental impacts. Therefore, novel excavation and construction methods should be further explored.

Field monitoring data can provide a less accurate but more readily applicable prediction of tunnel deformations induced by deep excavations, and these data are useful for a preliminary estimate of excavation performance. Compared with empirical results, numerical simulation is the most effective tool for evaluating the three-dimensional timespace effect and characterizing the tunnel stiffness $[6,8,16-18]$. Moreover, numerical solutions can predict the actual development of stress-strain in soft soils under complex construction conditions $[6,15]$. Therefore, using various methods (i.e., field monitoring and numerical analysis) to investigate deformation behaviours is vital for the construction of practical projects.

The objective of this study is to put forward a novel excavation and construction method, which is employed for the Taihu tunnel, the longest lake-crossing tunnel in China. To this end, the site characterization is introduced. Then the novel excavation and construction method is described in detail. The effects of the new construction method on the tunnel deformation were evaluated using finite element analysis combined with field monitoring data. The results revealed that the proposed method could effectively control the tunnel deformation and enhance the overall stability. This work provides an innovative idea for the design and construction of tunnel engineering, especially for extra-long underwater tunnels in soft soils.

\section{Site Characterization}

2.1. Project Overview. The Taihu tunnel crossing the Tai Lake, which is the third largest freshwater lake in China [19], is the longest lake-crossing tunnel in China, with a total length of $10.79 \mathrm{~km}$ and a width of $43.6 \mathrm{~m}$. The tunnel is an important part of the Su-Xi-Chang South Expressway, which connects the cities of Suzhou, Wuxi, and Changzhou (i.e., the Su-XiChang area) in China. Figure 1 shows the location of the Taihu tunnel. The cut-and-cover technique was adopted in the construction of the tunnel, combined with a cofferdam of double-raw steel sheet piles (DSSPs). Three sections, including the west shore section (WSS) (K23 + 900-K24+410), the lake section (LS) $(\mathrm{K} 24+410-\mathrm{K} 41+561)$, and the east shore section (ESS) $(\mathrm{K} 41+561-\mathrm{K} 43+560)$, comprised the tunnel excavation. Moreover, the depth from the water surface to the tunnel roof was in the range of 4-8 $\mathrm{m}$, and the thickness of the overburden soil beneath the lakebed ranged from $2 \mathrm{~m}$ to $6 \mathrm{~m}$. The maximum excavation depth was $20.3 \mathrm{~m}$.

2.2. Geological and Hydrogeological Conditions. Figure 2 shows the soil profile along the tunnel alignment, and Figure 3 summarizes the physical and mechanical properties of the main soil layers in the project area. The soil parameters were obtained with typical geotechnical tests (i.e., direct shear test, triaxial test, pumping tests, standard penetration tests, and oedometer tests), following the Chinese standard [20]. The stratigraphic units at the tunnel site are mainly composed of Quaternary Holocene miscellaneous fill and mucky clay layers, Upper Pleistocene clay, and silty clay and silt layers, as well as Devonian strongly weathered sandstone at the ESS. The site investigation identified three major soft soil layers along the tunnel alignment, namely, (1) 2 , (2) 4 , and (3) 2 . The pile foundation was suggested for crossing through these weak layers. In addition, there were no obvious large faults and folds in the project area.

The groundwater in the study area could be divided into pore water in the Quaternary Holocene formation, confined water in the silt layer, and fracture water in the strongly weathered sandstone. The silt layer is the main aquifer in the study area, for which the permeability coefficient is 1-2 orders of magnitude higher than that of the upper and lower layers. Moreover, the hydrochemical type of the surface water in the project area was $\mathrm{Cl} \bullet \mathrm{SO}_{4}-\mathrm{Na}$, and that of the groundwater was $\mathrm{HCO}_{3} \bullet \mathrm{SO}_{4}-\mathrm{Na} \bullet \mathrm{Ca}$.

\section{Excavation and Construction Method}

The traditional construction methods are not suitable for the Taihu tunnel, because of the unfavourable soil conditions, the stringent environmental requirements of Tai Lake, and the design request of the complex project. Therefore, an innovative excavation and construction method was proposed for the construction of the Taihu tunnel. Figure 4 schematically shows the proposed construction method. The construction steps are described in detail as follows:

Step 1: DSSPs were used to form several closed zones, that is, WSS and Zone \#1 (Figure 4(a)). Following the drainage of the lake water and the dredging work, the bored piles, cut-off walls, and cement mixed piles are prepared for the excavation of the closed zones.

Step 2: the levee and transverse DSSPs were removed for maintaining the smooth flow of construction vehicles, the space was excavated to the desired level along with the foundation dewatering, and the retaining structures were constructed to ensure the stability of foundation pits in WSS and Zone \#1 (Figure 4(b)). Meanwhile, Zone \#2 was formed by referring to Step 1.

Step 3: the tunnel ancillary structures in WSS and Zone \#1 were installed and Steps 1 and 2 were implemented 


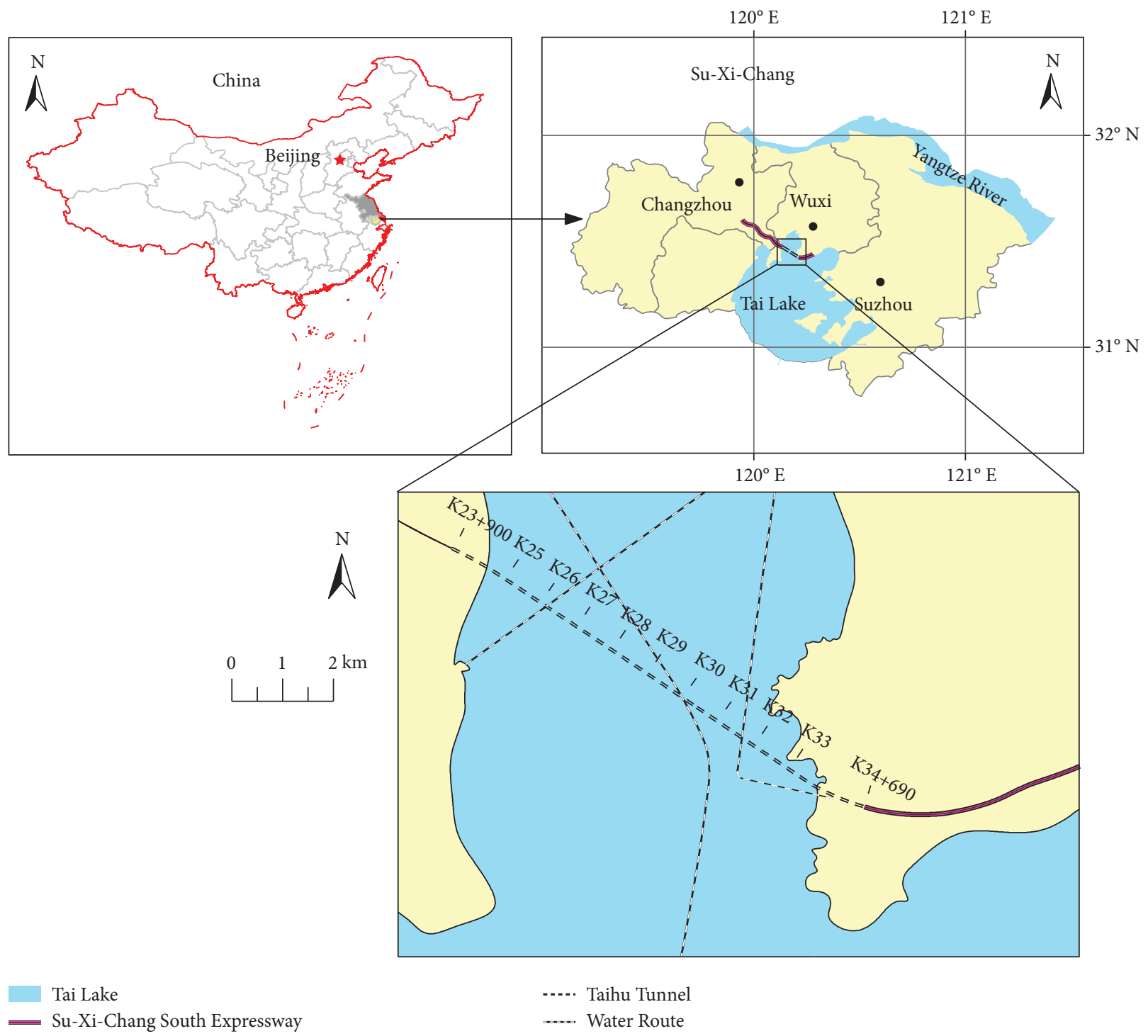

FIgURE 1: Location of the Taihu tunnel.

in Zone \#3 and Zone \#2, respectively (Figure 4(c)). Similarly, the transverse DSSPs located between Zone $\# 1$ and Zone \#2 were removed.

Step 4: The gap between the tunnel roof and the ground surface was filled in WSS and Zone \#1, the first earth cofferdam between WSS and Zone \#1 was constructed along the location of the transverse DSSPs in Step 2, and the truncated levee was backfilled (Figure 4(d)). Simultaneously, Steps 1, 2, and 3 were carried out in Zone \#4, Zone \#3, and Zone \#2, respectively. It should be noted that the earth cofferdam was constructed at the frequency of two zones.

Step 5: the longitudinal DSSPs of the WSS were removed to allow the lake water to flow normally, the soils in Zone \#2 were backfilled, the tunnel ancillary structures in Zone \#3 were constructed, and the soils in Zone \#4 were excavated (Figure 4(e)). In addition, the second earth cofferdam was built between Zone \#2 and Zone \#3.
In the proposed method, four zones were regarded as a unit, and different construction steps were carried out simultaneously in each zone. Hence, an assembly line for the tunnel excavation was established to accelerate the construction speed. The excavation did not cut off the normal flow of the lake water and the shipping routes because of the installation and removal of the DSSPs. Therefore, the proposed method had the advantages of low environmental impact, usage of recycled materials, and quick construction.

\section{Field Monitoring}

To monitor the deformation behaviour of the tunnel, a longterm comprehensive field instrumentation program was conducted along the tunnel alignment. Taking Zone \#1 as an example, the observed deformation behaviours included vertical and horizontal movements of the DSSPs, vertical movements at the tops of the bored piles, deflections of the bored piles, ground surface settlements, and settlements of the earth cofferdam. 


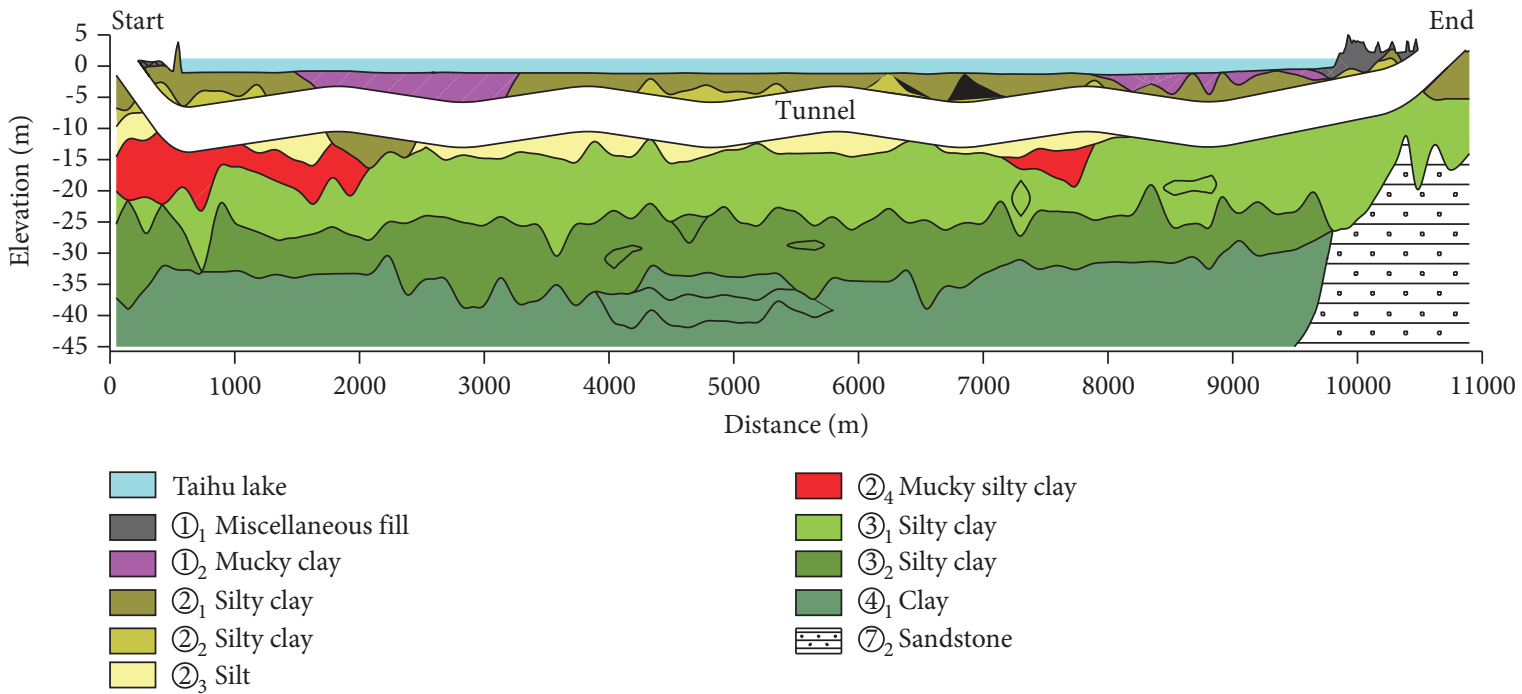

Figure 2: Soil profile along the tunnel alignment.

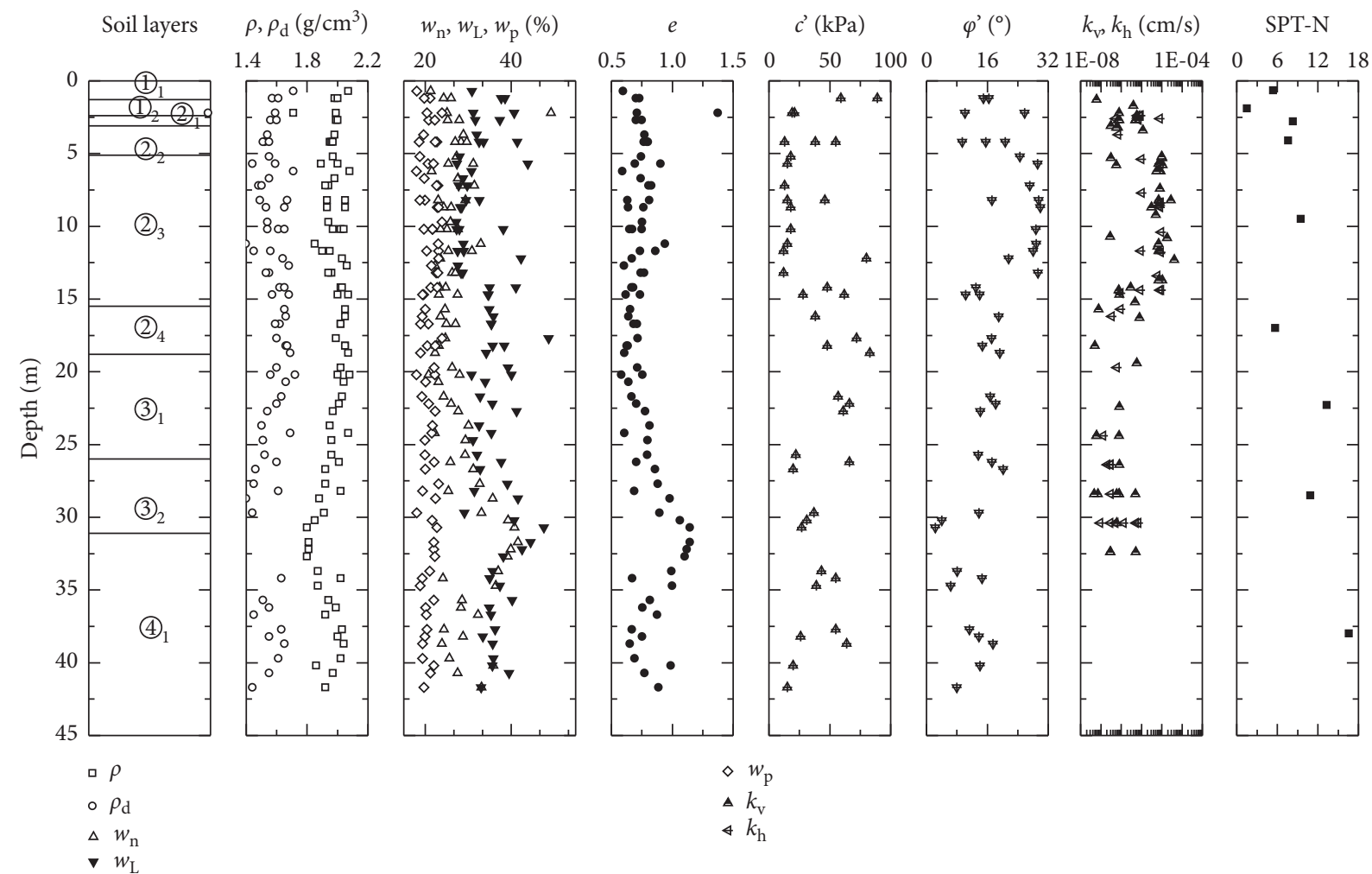

Figure 3: Geotechnical parameters of soft soils.

4.1. Retaining Structures. Figure 5 presents a typical cross section on the north side of Zone \#1. Clearly, the DSSPs connected by the reinforcement were $15 \mathrm{~m}$ long, and the embedded length was $10 \mathrm{~m}$. The space above the ground surface with a $6 \mathrm{~m}$ width was filled with cohesive soil whose compaction was at least $90 \%$. The cut-off wall was set at the top of the slope with a length of $16.3 \mathrm{~m}$ and a width of $0.85 \mathrm{~m}$. The height of the two-level slope was $7.2 \mathrm{~m}$ with a slope ratio of $1: 1.5$, while the depth supported by the bored piles was $8.9 \mathrm{~m}$. The reinforcement ratio of the normal section of the bored piles was $0.45 \%$, and the bending moment capacity was $550 \mathrm{kNm}$. To restrain the lateral deflections of the bored piles, two levels of struts were constructed. The first level strut was made of C30 concrete with a diameter of $0.8 \mathrm{~m}$ and a spacing of $1.2 \mathrm{~m}$, whereas $\Phi 609$ @ 16 steel tubes were used for the second level. Moreover, the cement mixed piles were 


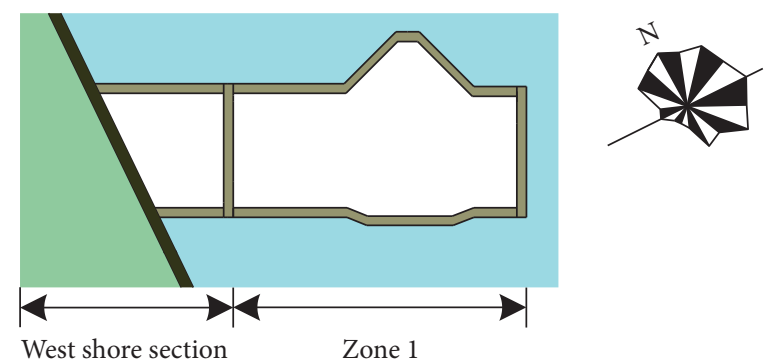

(a)

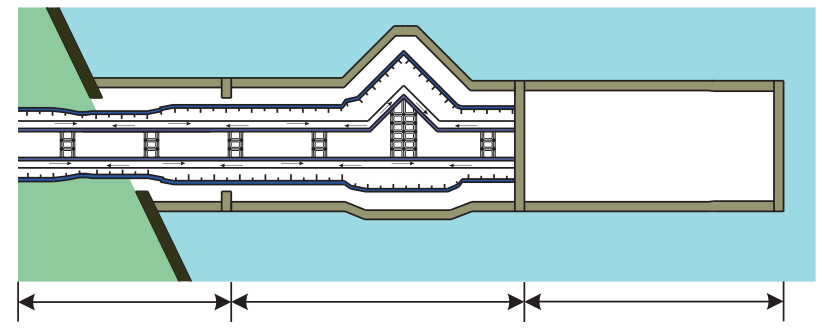

West shore section Zone 1 Zone 2

(b)

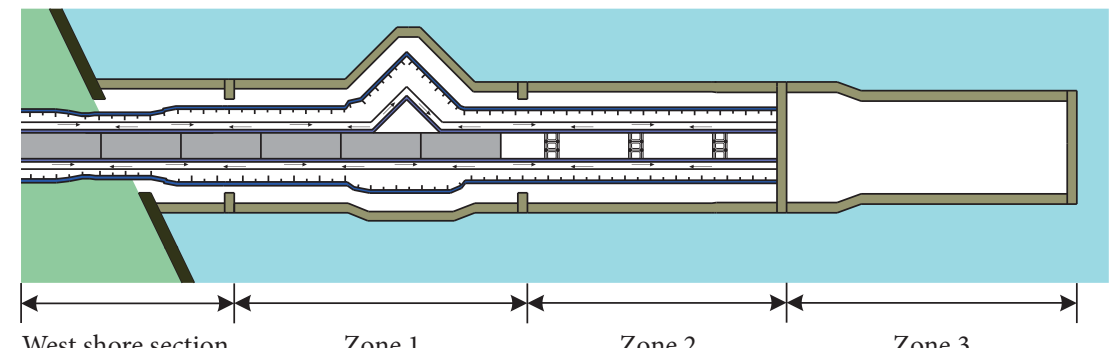

(c)

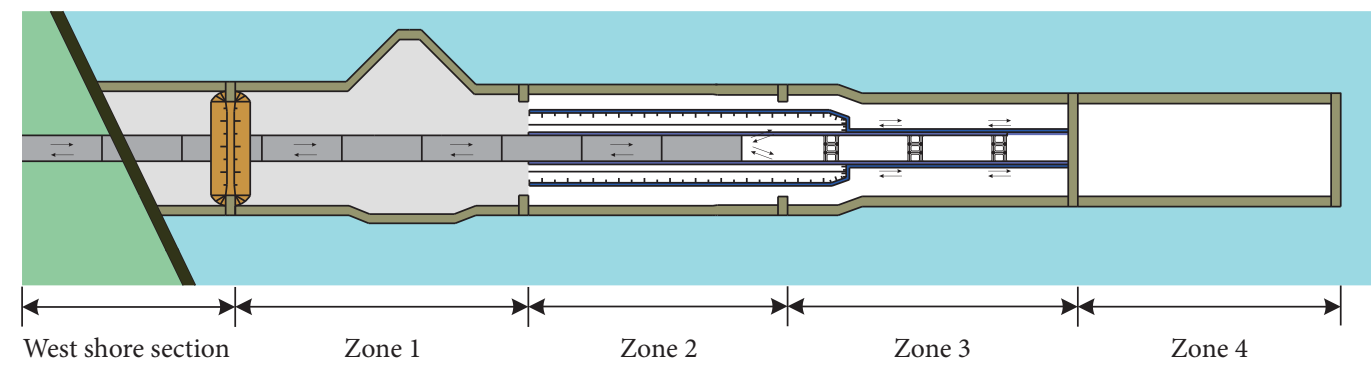

(d)

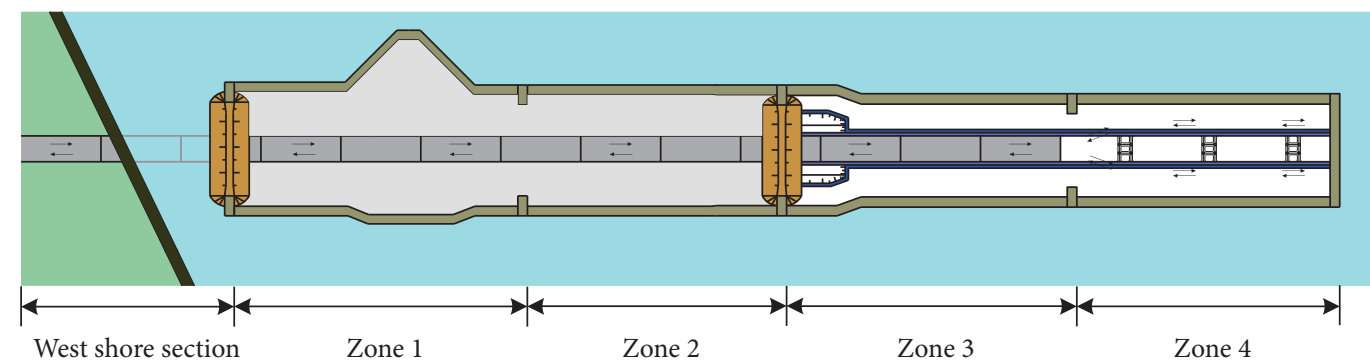

(e)
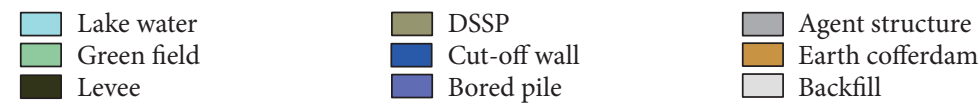

$\rightleftarrows$ Vehicle

एग. Slope

酉 Retaining structure

Figure 4: Schematic diagram of the novel construction method. (a) Step 1, (b) Step 2, (c) Step 3, (d) Step 4, and (e) Step 5. 


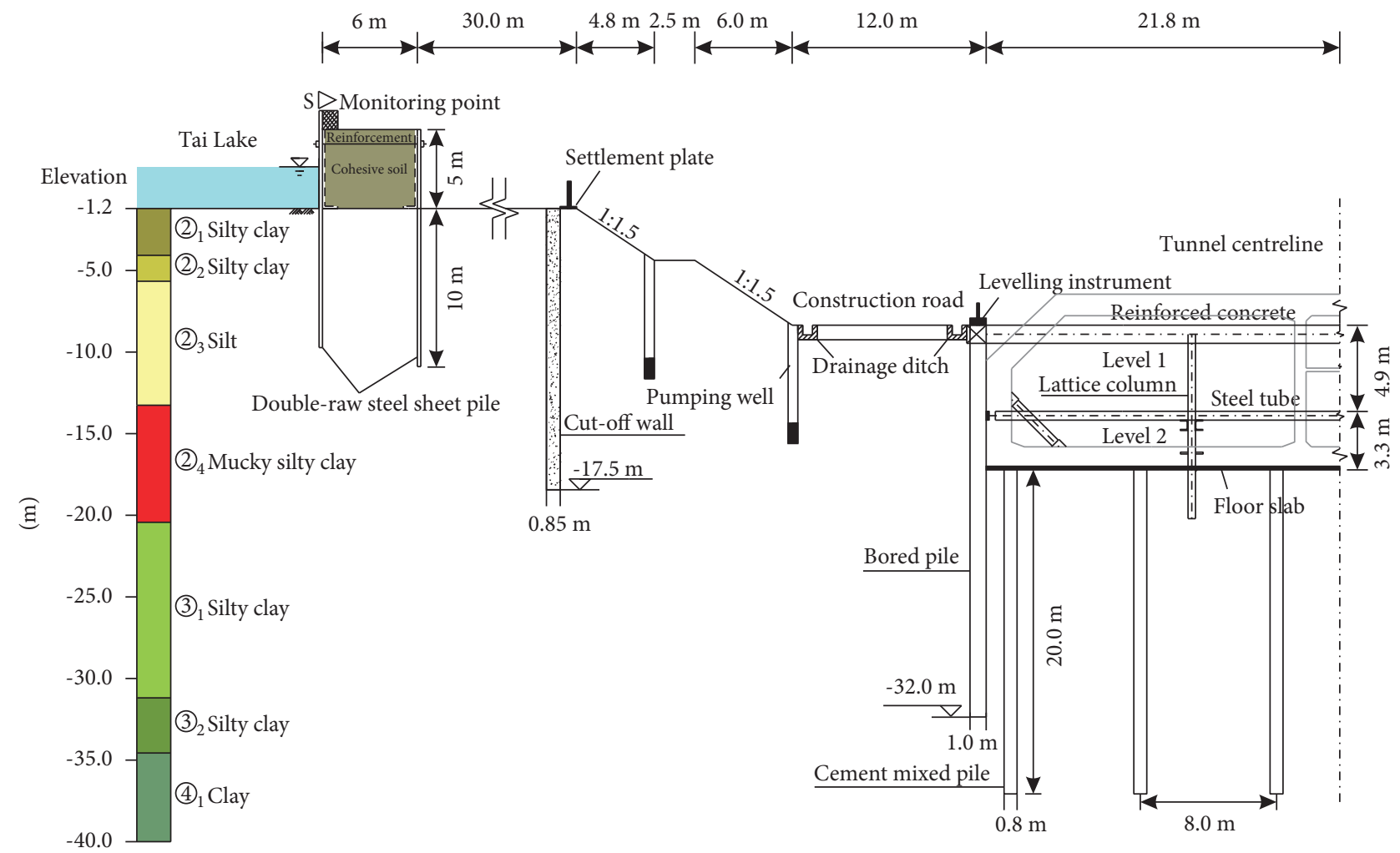

Figure 5: Typical cross section on the north side of Zone \#1.

arranged to reinforce the subsoil beneath the bottom of the foundation pit, with a pile spacing of $8.0 \mathrm{~m}$, a diameter of $0.8 \mathrm{~m}$, and a length of $20.0 \mathrm{~m}$.

The earth cofferdam, as a secondary transverse cofferdam, was used to prevent the lake water from entering the excavation after the removal of the DSSPs. The height, top width, bottom width, and slope ratio of the earth cofferdam located between WSS and Zone \# 1 were $5.0 \mathrm{~m}, 3.0 \mathrm{~m}, 33.0 \mathrm{~m}$, and $1: 3$, respectively, as shown in Figure 6 .

4.2. Construction Stages. Table 1 summarizes the main construction stages of Zone \#1. The site work began with the construction of the DSSPs, followed by the drainage of the lake water and the dredging work in the zone. After the construction of the bored piles, cut-off walls, and cement mixed piles, the excavation activities started on September 10, 2018, and ended on April 13, 2019. To reduce the tunnel deformation, two-level struts were installed promptly after the corresponding soil layer was excavated. The tunnel ancillary structures were constructed with the casting of floor slabs and the removal of the struts, and the soil was backfilled from the tunnel roof to the ground surface. Finally, the earth cofferdam was completed on May 13, 2020, and was monitored after the removal of the longitudinal DSSPs of the WSS.

4.3. Instrumentation. Figure 7 displays the instrumentation layout of Zone \#1. The movements of the DSSPs were observed by 74 monitoring points, numbered as S1 to S74 with approximately $15 \mathrm{~m}$ intervals. The deflections of bored piles were monitored by 40 inclinometer tubes (designated as B1 to B40 and spaced approximately $20 \mathrm{~m}$ apart) that were fixed to the reinforcement cage for each instrumented panel before concreting. The resolution of each inclinometer was $0.1 \mathrm{~mm} / 500 \mathrm{~mm}$ gauge length. Moreover, the vertical movements at the tops of bored piles were measured using levelling instruments. To survey the ground settlements, 44 monitoring points, designated as G1 to G44 and at approximately $20 \mathrm{~m}$ intervals, were set at the top of the slope in Zone \#1. Twelve monitoring points for the settlements of the earth cofferdam are shown in Figure 7. The data reading for the earth cofferdam had to be taken after removing the longitudinal DSSPs of the WSS, and the frequency of data reading was once every three days.

Unfortunately, some inclinometer tubes and settlement points were damaged during the construction. Therefore, the remaining available data are provided in the electronic supplementary files, which can be found online at https:// www.researchgate.net/publication.

\section{Observed Deformation Behaviours}

5.1. Vertical Movements of DSSPs. The DSSPs acting as a cofferdam were used to prevent lake water from entering the excavation, which was directly related to the stability and safety of the whole project. Therefore, it was necessary to monitor both the vertical and horizontal movements of the DSSPs during excavation. Figure 8 shows the development of the vertical movements of the longitudinal DSSPs during 


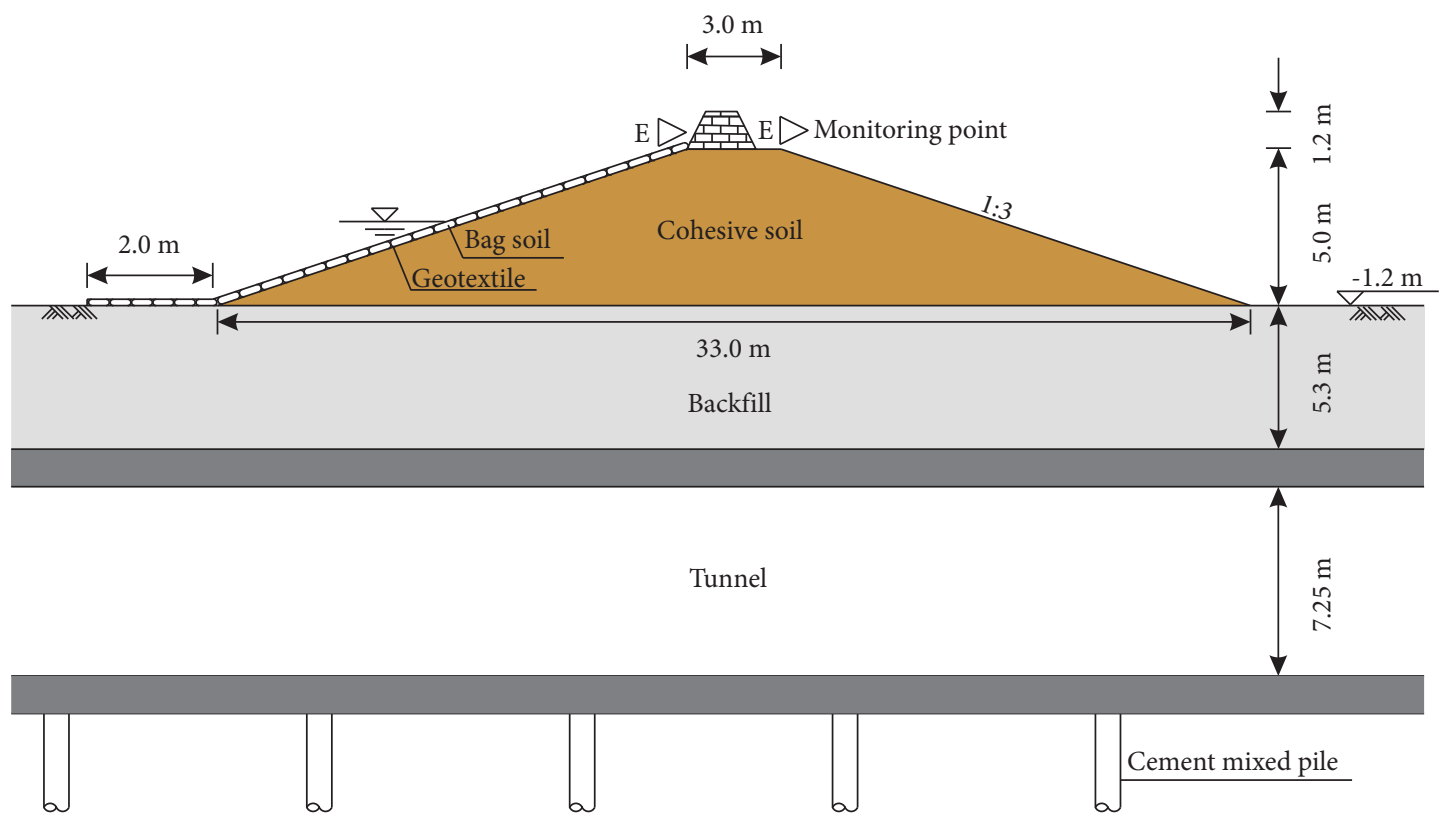

FIGURE 6: Cross section of the earth cofferdam located between WSS and Zone \#1 along the tunnel centreline.

TABLE 1: Main construction stages of Zone \#1.

\begin{tabular}{|c|c|c|}
\hline Stages & Construction activity & Date $(\mathrm{mm} / \mathrm{dd} /$ year $)$ \\
\hline $1(\mathrm{a})$ & Construction of DSSPs & $04 / 01 / 2018-06 / 27 / 2018$ \\
\hline $1(\mathrm{~b})$ & Discharge of lake water and dredging work & $06 / 28 / 2018-07 / 07 / 2018$ \\
\hline $1(\mathrm{c})$ & Construction of bored piles, cut-off walls, and cement mixed piles & $07 / 18 / 2018-09 / 08 / 2018$ \\
\hline $2(\mathrm{a})$ & Removal of embankment or transverse DSSPs & $09 / 09 / 2018$ \\
\hline 2(b) & Excavation of the first layer of subsoil with thickness of $3.2 \mathrm{~m}$ & $09 / 10 / 2018-10 / 16 / 2018$ \\
\hline $2(c)$ & Excavation of the second layer of subsoil with thickness of $4 \mathrm{~m}$ & $10 / 17 / 2018-12 / 19 / 2018$ \\
\hline $2(\mathrm{~d})$ & Installation of struts at Level 1 & $12 / 20 / 2018-12 / 31 / 2018$ \\
\hline $2(\mathrm{e})$ & Excavation of the third layer of subsoil with thickness of $5.3 \mathrm{~m}$ & $01 / 01 / 2019-03 / 05 / 2019$ \\
\hline $2(f)$ & Installation of struts at Level 2 & 03/06/2019-03/14/2019 \\
\hline $2(\mathrm{~g})$ & Excavation of the fourth layer of subsoil with thickness of $3.6 \mathrm{~m}$ & $03 / 15 / 2019-04 / 13 / 2019$ \\
\hline $3(\mathrm{a})$ & Casting of floor slabs & 04/14/2019-06/19/2019 \\
\hline $3(\mathrm{~b})$ & Removal of struts at Level 2 & $06 / 20 / 2019-06 / 27 / 2019$ \\
\hline $3(\mathrm{c})$ & Construction of side walls of tunnel & 06/28/2019-09/09/2019 \\
\hline $3(d)$ & Construction of inclined steel struts & 09/09/2019-09/18/2019 \\
\hline $3(\mathrm{e})$ & Removal of struts at Level 1 & $09 / 19 / 2019-09 / 26 / 2019$ \\
\hline $3(\mathrm{f})$ & Construction of tunnel roof & 09/27/2019-05/07/2020 \\
\hline $3(\mathrm{~g})$ & Removal of inclined steel struts & $05 / 08 / 2020-05 / 21 / 2020$ \\
\hline $4(\mathrm{a})$ & Backfilling of soils & $05 / 22 / 2020-05 / 29 / 2020$ \\
\hline $4(\mathrm{~b})$ & Construction of earth cofferdam or truncated embankment & $06 / 01 / 2020-06 / 09 / 2020$ \\
\hline 5 & Removal of longitudinal DSSPs & $06 / 20 / 2020-06 / 27 / 2020$ \\
\hline
\end{tabular}

excavation. Obviously, the longitudinal DSSPs at both sides of Zone \#1 experienced significant settlements during construction. Following the casting of floor slabs and the installation of ancillary structures, the settlements tended to stabilize with time, implying that the floor slabs and the ancillary structures could help stabilize the vertical movements of the DSSPs. The measured maximum movement was approximately $28.05 \mathrm{~mm}$ along S12 on the north side of Zone \#1, still being controlled within the permitted value (i.e., $30 \mathrm{~mm}$ ).

Figure 9 shows the development of the vertical movements of the transverse DSSPs located between Zone \#1 and
Zone \#2 during the excavation. Compared with the vertical movements of the longitudinal DSSPs, those of the transverse DSSPs along S41 to S45 were relatively small, approximately -10 to $15 \mathrm{~mm}$. This suggests that the excavation of the foundation pit strongly affects the longitudinal DSSPs more than the transverse DSSPs.

5.2. Horizontal Movements of DSSPs. Figure 10 presents the variation in the horizontal movements of the longitudinal DSSPs during excavation. Overall, the horizontal movements of the longitudinal DSSPs were positive, indicating 


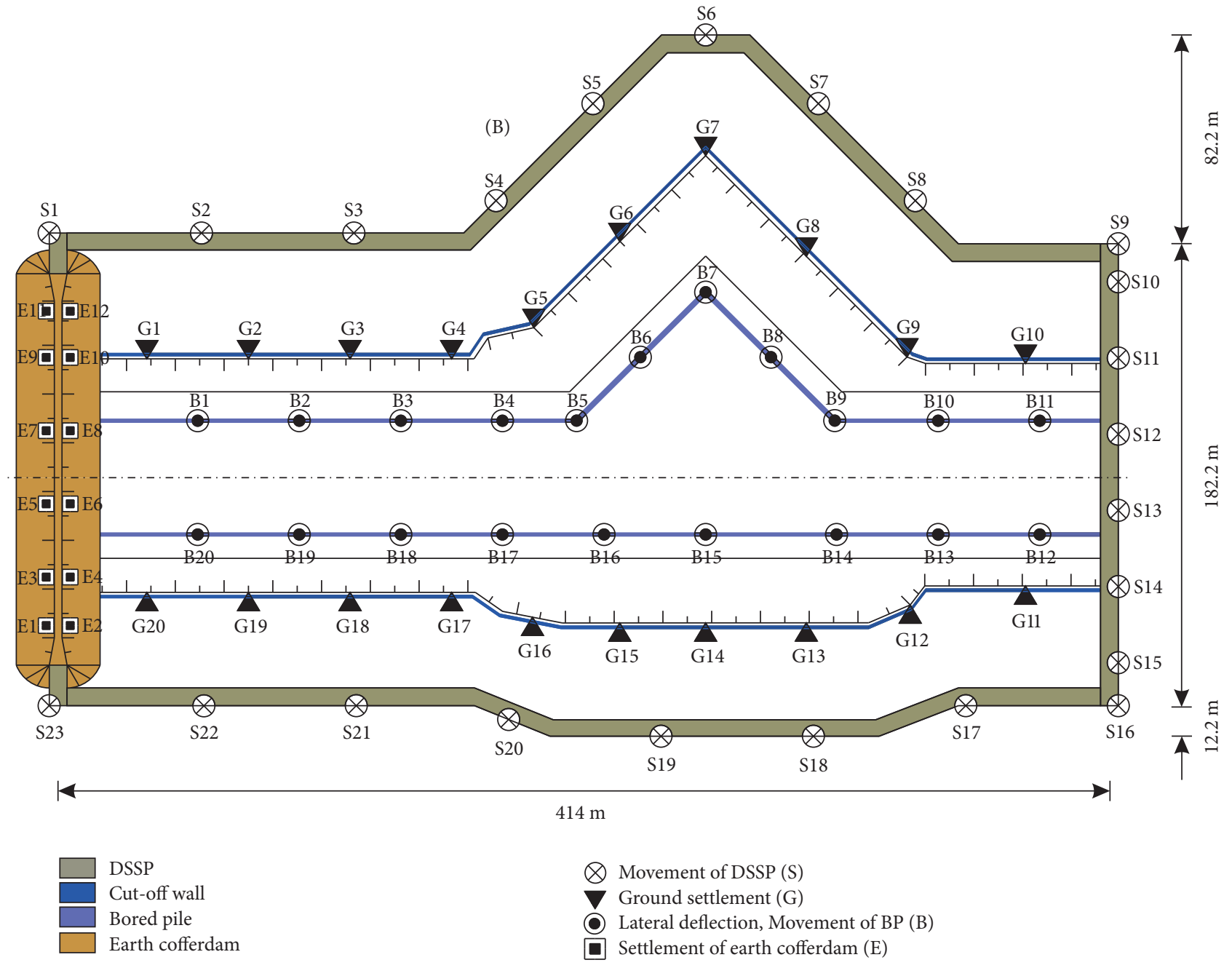

FIGURE 7: Instrumentation layout of Zone \#1.

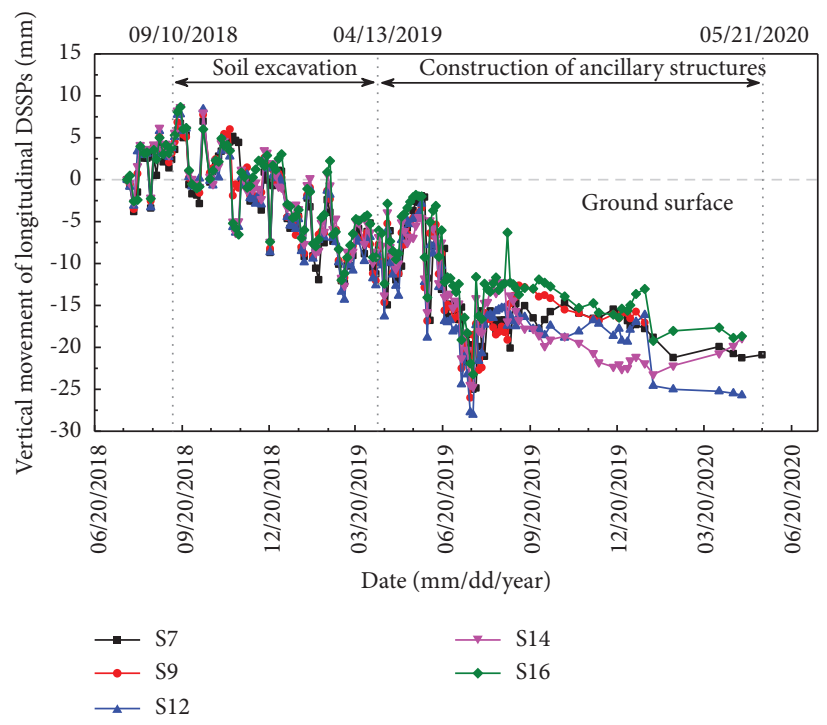

(a)

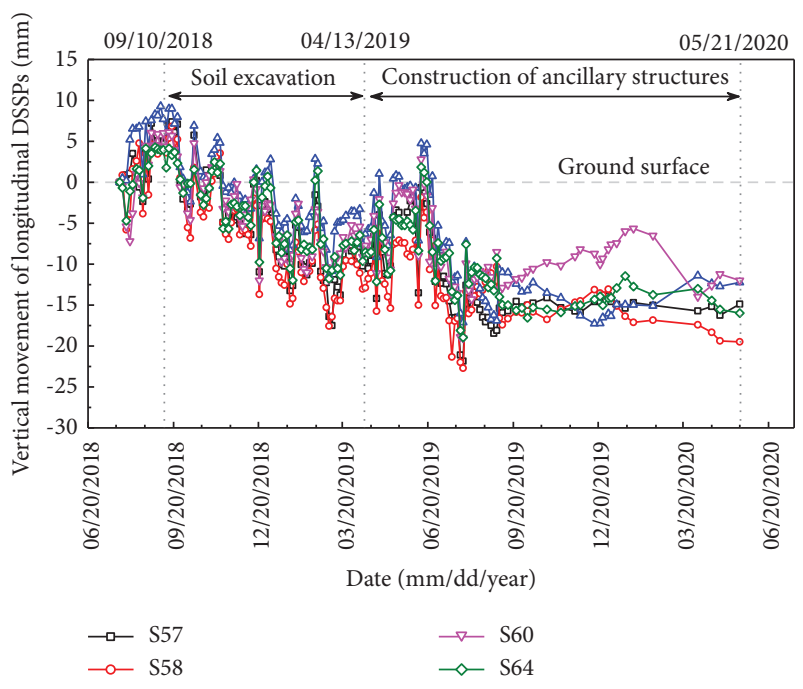

(b)

FIGURE 8: Development of the vertical movements of the longitudinal DSSPs during construction. (a) On the north side of Zone \#1 and (b) on the south side of Zone \#1. 


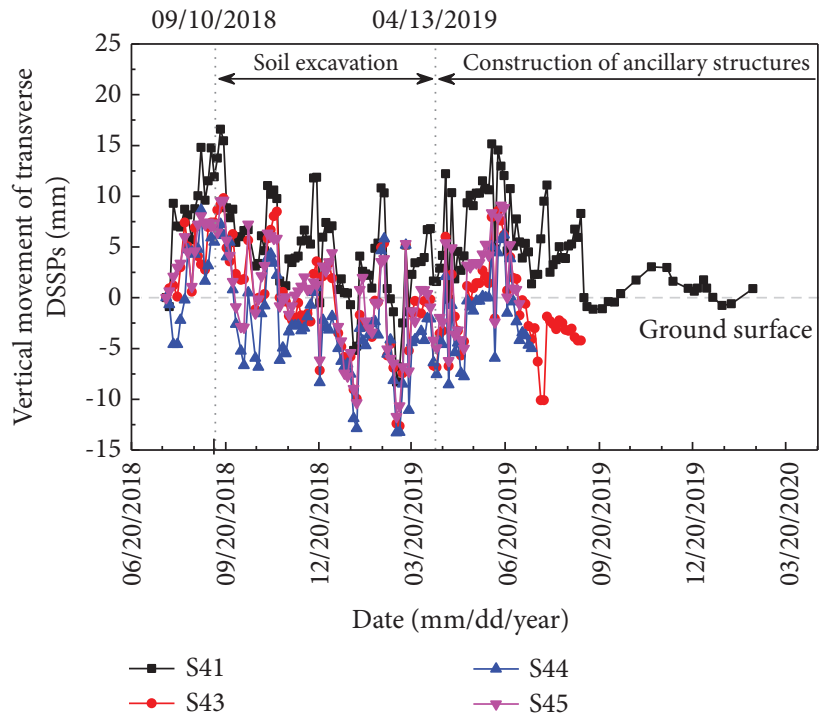

FIGURE 9: Development of the vertical movements of the transverse DSSPs.

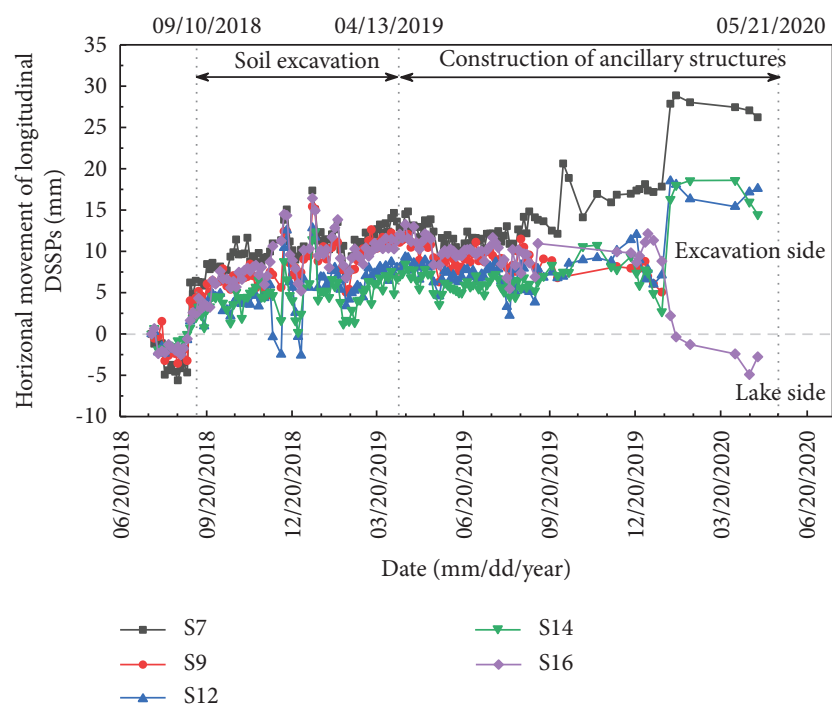

(a)

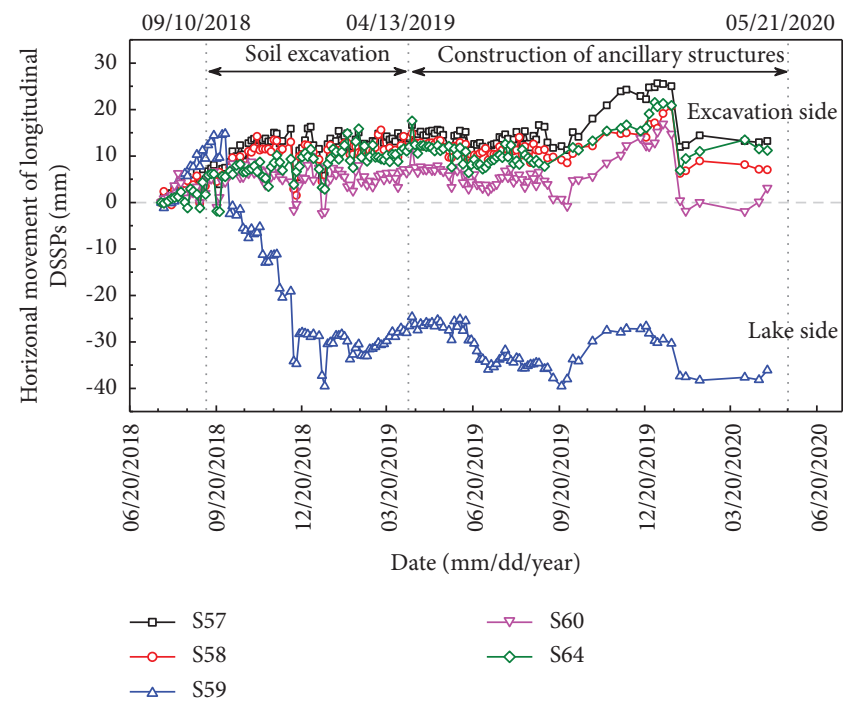

(b)

Figure 10: Development of the horizontal movements of the longitudinal DSSPs during construction. (a) On the north side of Zone \#1 and (b) on the south side of Zone \#1.

that the longitudinal DSSPs moved to the excavation side in the horizontal direction. The horizontal movements increased rapidly in Stages 1(b) and 1(c) (Table 1) and then fluctuated widely during the soil excavation, which revealed that the soil excavation had less influence on the horizontal movements than on the vertical movements of the longitudinal DSSPs. Some factors have contributed to these horizontal movements: (1) the hydrostatic pressure of the lake water, (2) the hydrodynamic pressure caused by the wave action, and (3) the force unbalance because of the excavation. However, the data for the monitoring point S59 exceeded the control value (i.e., $30 \mathrm{~mm}$ ). Thus, the corresponding measures had to be taken to control the deformation.
Figure 11 shows the development of the horizontal movements of the transverse DSSPs during excavation. Obviously, the magnitudes of the horizontal movements of the transverse DSSPs were smaller than those of the longitudinal DSSPs. This likely occurred because the drainage of lake water in Zone \#2 reduced the unbalance force on the transverse DSSPs. Some rapid drops occurred around January 20,2019, indicating that the transverse DSSPs moved to the lake side. The bagged soil arranged behind the DSSPs might have contributed to this phenomenon.

5.3. Deflections of Bored Piles. The lateral deflection of the bored piles could be related to the site excavation and the 


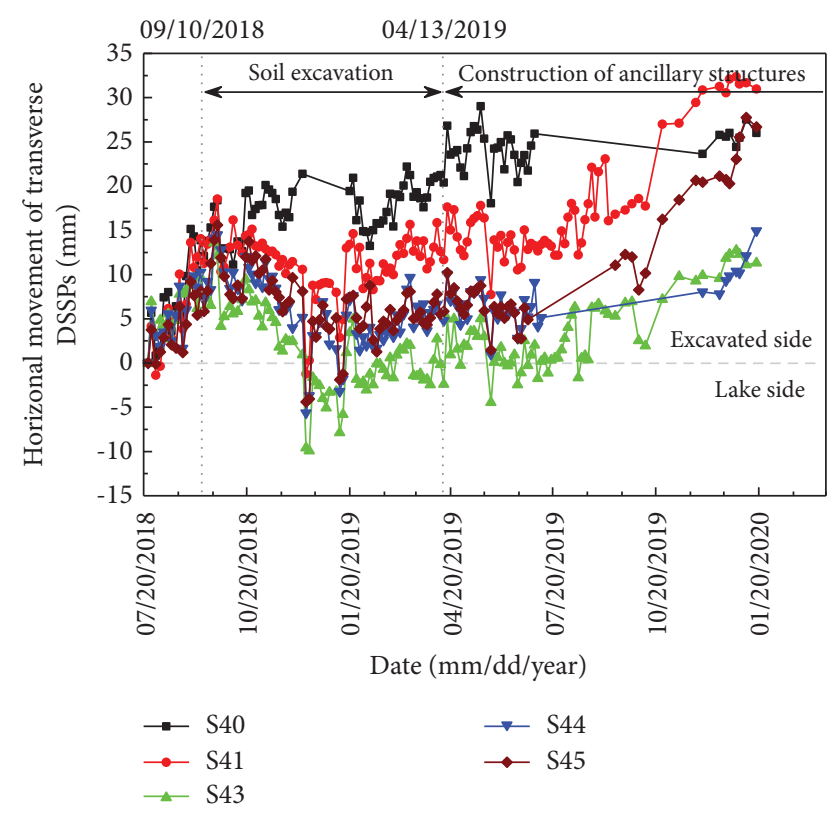

FIgURE 11: Development of the horizontal movements of the transverse DSSPs.

casting of the floor slabs. The development of the lateral deflections of the bored piles at B36 and the maximum deflections at several monitoring points is presented in Figure 12. The bored piles began to develop deep-seated movements toward the excavation side as the excavation proceeded to lower levels in Stages 2(e) and 2(f). The lateral deflection reached its maximum during the subsequent construction of the floor slab at Stage 3(a). The maximum deflection of the bored piles was $8.95 \mathrm{~mm}$ at B36 on the south side of Zone \#1.

Figure 13 shows the relationship between the measured maximum deflection at each excavation level, $\delta_{h m}$, and the excavation depth, $H_{\mathrm{e}}$. Obviously, the measured $\delta_{h m}$ was distributed between $\delta_{h m}=0.006 \% H_{e}$ and $\delta_{h m}=0.06 \% H_{e}$. Some case histories are presented in Figure 13 for the purpose of comparison. These case histories indicate that the upper and lower boundaries of $\delta_{h m}$ at this site are significantly smaller than those reported by Clough and O'Rourke [21] for excavations in stiff clay, by Hashash et al. [22] for excavations in medium-stiff Boston clay, and by Tan and Wei [6] for excavations in soft Shanghai clay. Therefore, the deformations of the bored piles were relatively smaller than those reported in the literature. The extensive use of underground structures such as cut-off walls and cement mixed piles, the rapid cast of floor slabs, and the quick construction of bored piles may contribute to this phenomenon. It is noteworthy to mention that the influence of the seepage force on the lateral deflection of bored piles is not considered because of the waterproofing structures.

Figure 14 summarizes the normalized maximum deflection, $\delta_{h m} / H_{e}$, and the normalized retaining system stiffness, $E I /\left(\gamma_{w} h^{4}\right)$, at this site, in which $E I /\left(\gamma_{w} h^{4}\right)$ was defined by Clough et al. [23]. The factor of safety against the basal heave $F O S_{\text {base }}$ was calculated based on the method used by Terzaghi [24]. The six case histories reported by Wang et al. [25] are also included in this figure for comparison. As illustrated, the observed $\delta_{h m} / H_{e}$ from the excavation fell within the ranges proposed by Clough et al. [23], and it appeared to be independent of FOS base.

5.4. Vertical Movements at the Top of Bored Piles. Figure 15 illustrates the distribution of the vertical movements at the top of bored piles during construction. Beyond expectation, the bored piles experienced significant heaves rather than settlements during the excavation. The excavation of upper soils and the release of stress resulted in the swelling of soils at the bottom of the foundation pit, and then the elastic and plastic rebound of soils happened [6]. Beyond that, the soil movements around the bored piles might have also caused this phenomenon. The measured maximum movement was approximately $21.51 \mathrm{~mm}$ along B4 on the north side of the excavation.

5.5. Ground Surface Settlements. Figure 16 summarizes the development of the ground settlements $\delta_{\mathrm{vm}}$ at G3, G39, G40, G41, G42, and G43. The ground settlements increased with the excavation of the pit until the casting of floor slab and then tended to be stable. The settlement on the north side of the pit exhibited a similar tendency to that on the south side. The fluctuation in the settlement at the slope top of the pit was observed during the excavation of the subsoil, which may be due to two factors: (1) rainfall and (2) vehicles frequently passing at approximately $13.3 \mathrm{~m}$. Moreover, the measured ground settlement was in the range of $5-15 \mathrm{~mm}$, with the maximum value of $11.25 \mathrm{~mm}$ at G42. Therefore, based on the new construction method, the ground settlements of the foundation pit were controlled within the permitted value, i.e., $30 \mathrm{~mm}$.

Figure 17 plots the relationships between the measured maximum ground settlement, $\delta_{\mathrm{vm}}$, and each excavation depth, $H_{\mathrm{e}}$, in which three-case histories from Taipei [21], Boston [22], and Shanghai [6] were introduced for the purpose of comparison. It can be shown that $\delta_{\mathrm{vm}}$ was bounded by $\delta_{v m}=0.01 \% H_{e}$ and $\delta_{v m}=0.1 \% H_{e}$. The developed boundaries of $\delta_{\mathrm{vm}}$ for Zone \#1 were much lower than those of Clough and O'Rourke [21] for excavations in stiff Taipei clay, Tan and Wei [6] in soft Shanghai clay, and Hashash et al. [22] in medium-stiff Boston clay.

To better illustrate the characteristics of the settlement profiles, the ground surface settlement was normalized by its corresponding $\delta_{\mathrm{vm}}$, as plotted in Figure 18. Two common profiles and several available data collected by Wang et al. [26] in Shanghai soft clay are also shown for comparison in the same figure. It can be seen that the $\delta_{v} / \delta_{v m}$ measured from the excavation ranged from 0.21 to 0.98 , which confirmed the effectiveness of the construction scheme and the related measures.

5.6. Settlements of Earth Cofferdam. After the removal of the longitudinal DSSPs of the WSS, the earth cofferdam was constructed to prevent the lake water from entering the excavation site, on June 10, 2020. Figure 19 shows the 

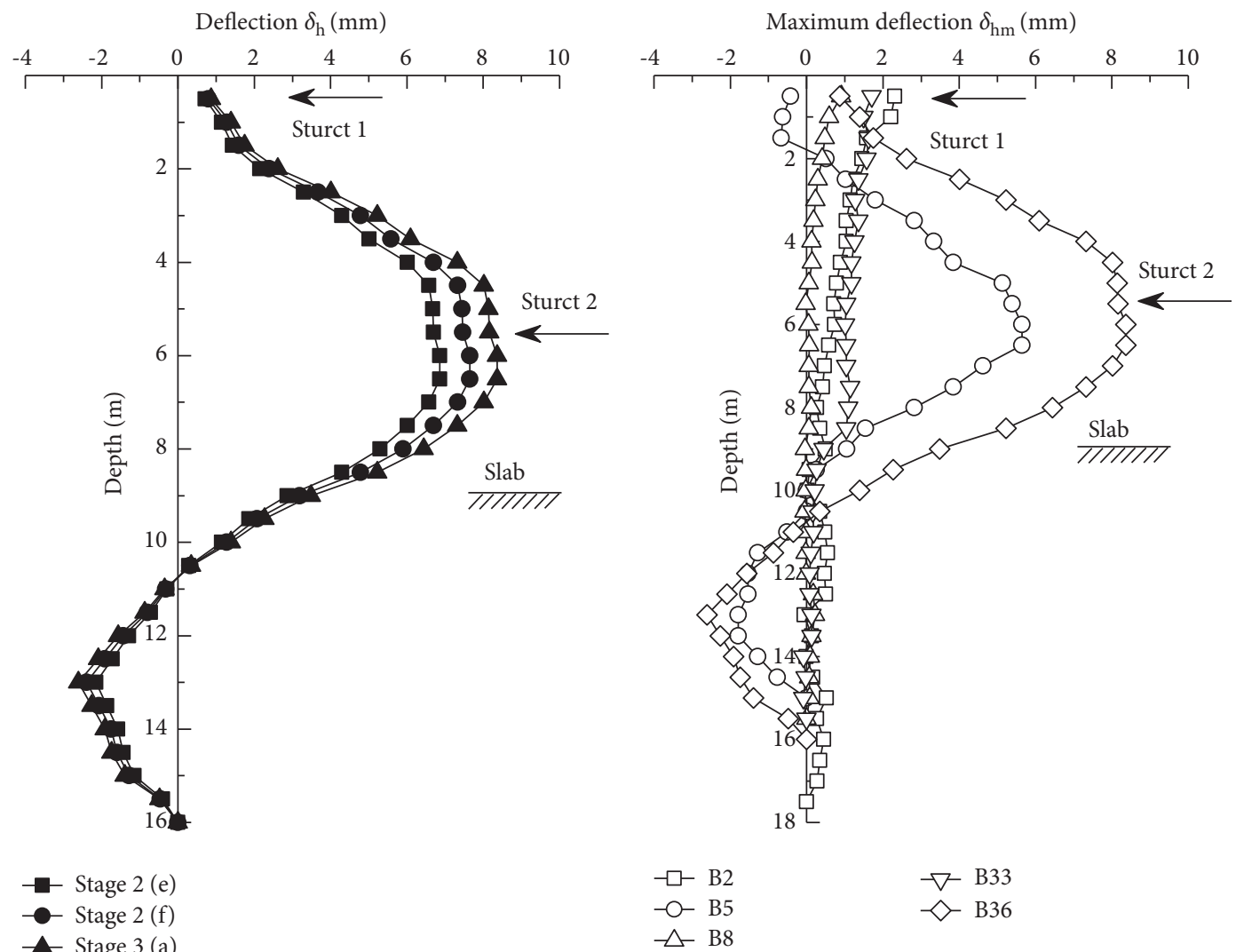

(a)

(b)

FIGURE 12: Lateral deflection of bored piles along depth. (a) Development of deflections at B36 and (b) maximum deflections at B2, B5, B8, $\mathrm{B} 33$, and B36.

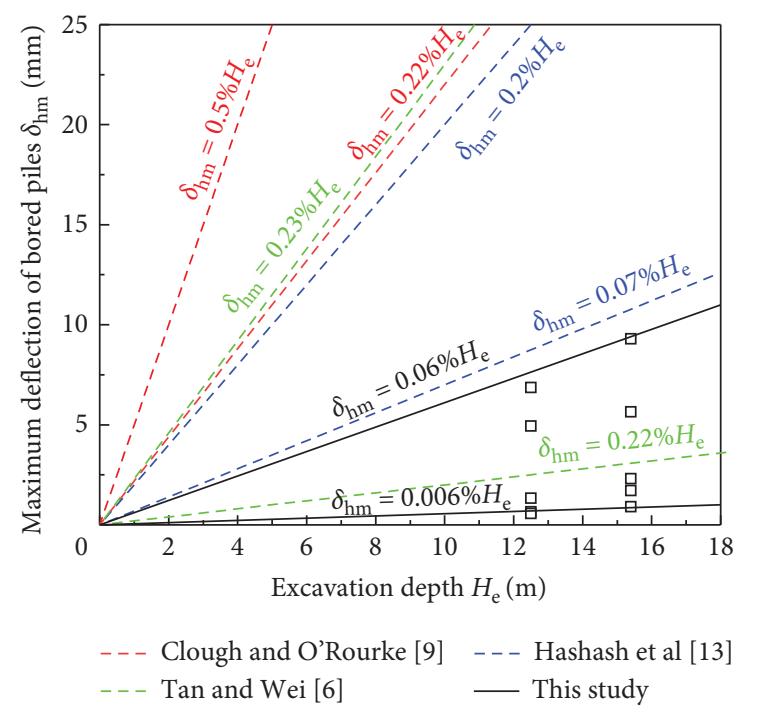

FIGURE 13: Relationship between the maximum deflections of bored piles and the excavation depths.

measured surface settlements of the earth cofferdam. The settlements on the upstream side were found to be in the range of 11-26 mm, while that on the excavation side ranged from $0.5 \mathrm{~mm}$ to $14.0 \mathrm{~mm}$.

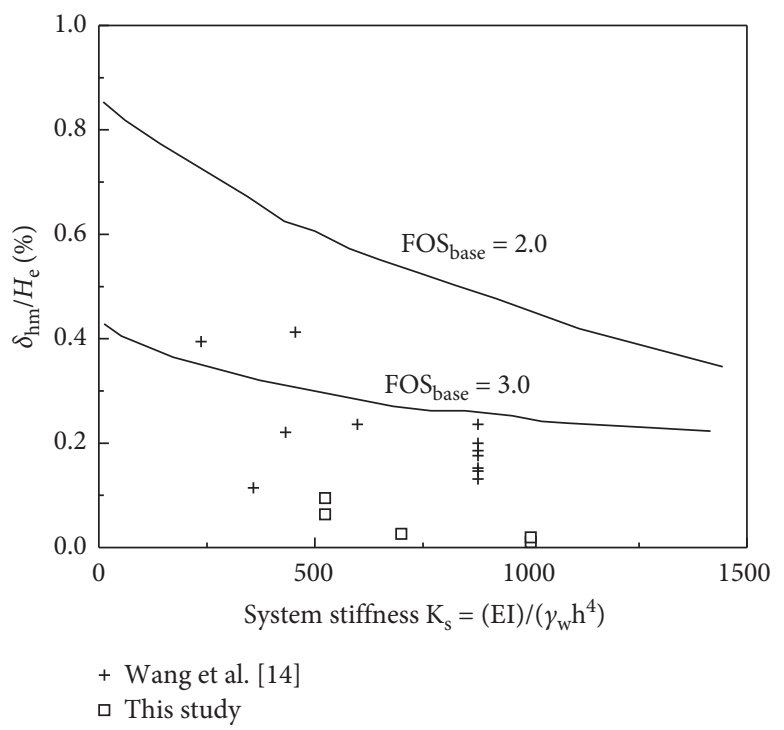

FIGURE 14: Relationship between the normalized maximum deflection and the system stiffness.

\section{Numerical Simulation}

Based on the field monitoring data in this study, it is found that the magnitudes of the vertical movements of the DSSPs 


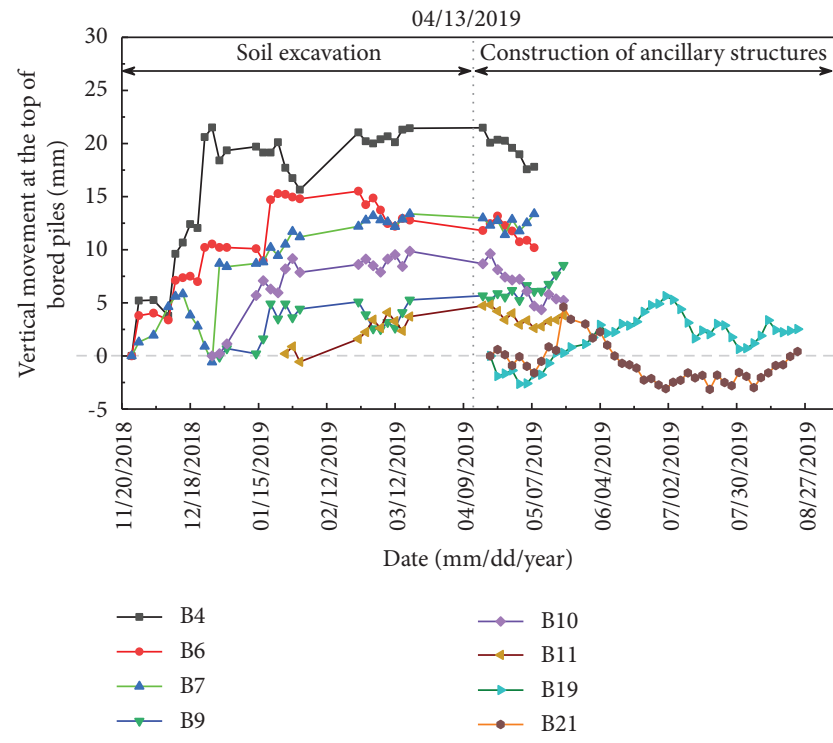

(a)

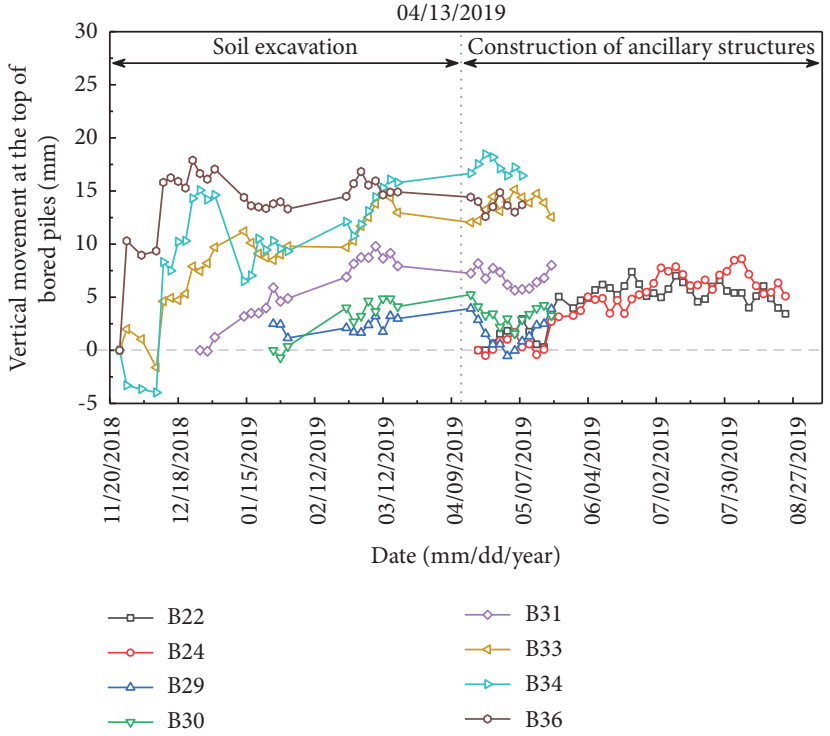

(b)

FIGURE 15: Distribution of the vertical movements at the top of bored piles. (a) On the north side of Zone \#1 and (b) on the south side of Zone \#1.

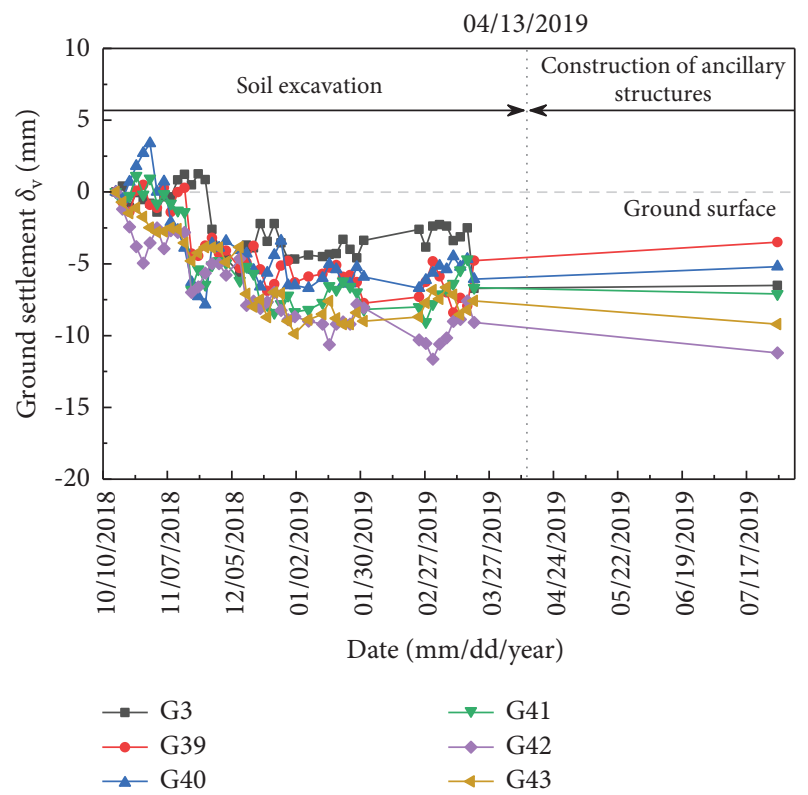

Figure 16: Ground surface settlements at G3, G39, G40, G41, G42, and G43.

were larger than those of the horizontal movement. Additionally, the maximum deflection and settlement were atypical to those reported in the literature. To better show the performance of the foundation pit, a plane-strain numerical model was established based on the field case study.

6.1. Finite Element Numerical Model. A finite element model, solved with PLAXIS 2D software, was built as shown in Figure 20. The length and the depth of the model

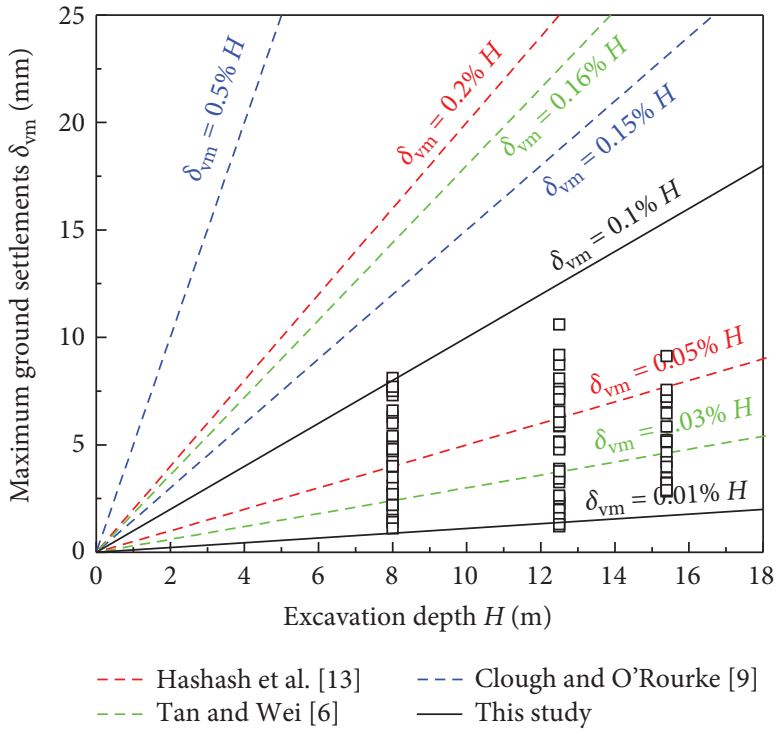

Figure 17: Relationship between the maximum ground settlement and the excavation depth.

were $100 \mathrm{~m}$ and $42 \mathrm{~m}$, respectively. The displacements were constrained in both directions at the bottom, and zero horizontal displacement was imposed at the lateral boundaries. The silt layer was simulated as being in the drained condition, whereas the clay layers were modeled as being in the undrained condition. Moreover, the hydrostatic pressure load had a linear relationship with the water depth on the DSSPs. The Mohr-Coulomb constitutive model was adopted in the numerical analysis. The retaining structures (e.g., bored piles, mixed cement piles, and cut-off wall) were assumed to be linear elastic materials, referring 


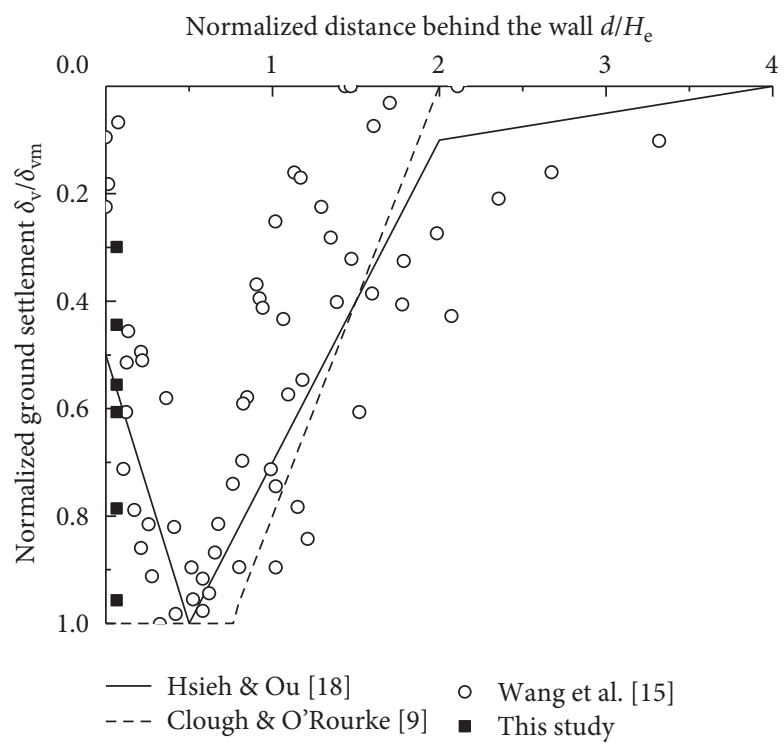

FIGURE 18: Normalized ground surface settlement perpendicular to the excavation area.

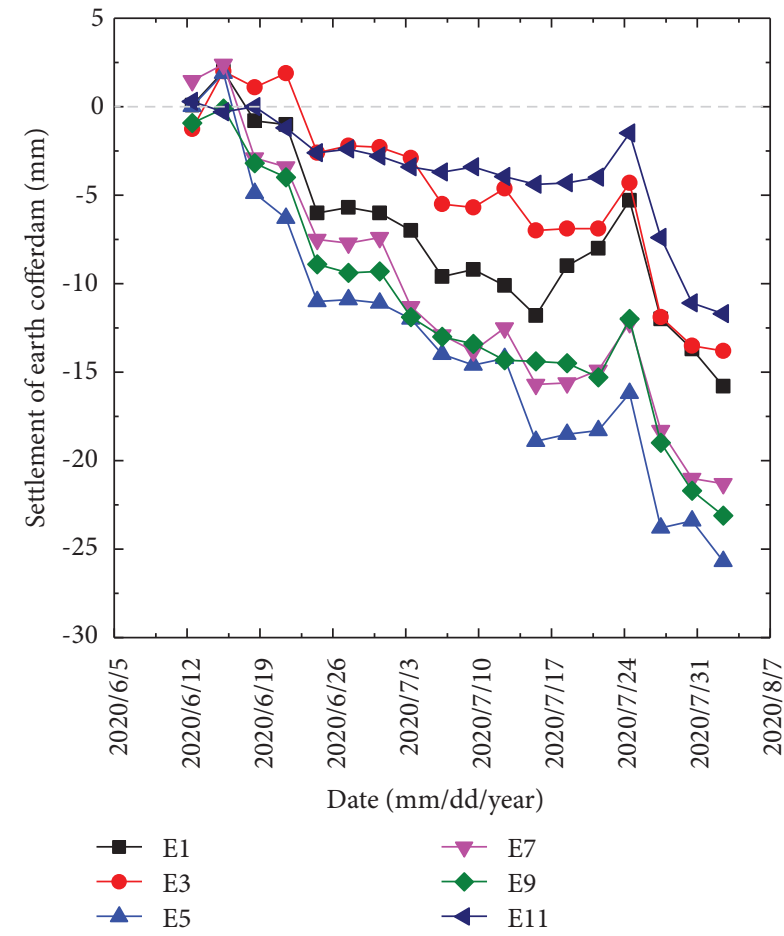

(a)

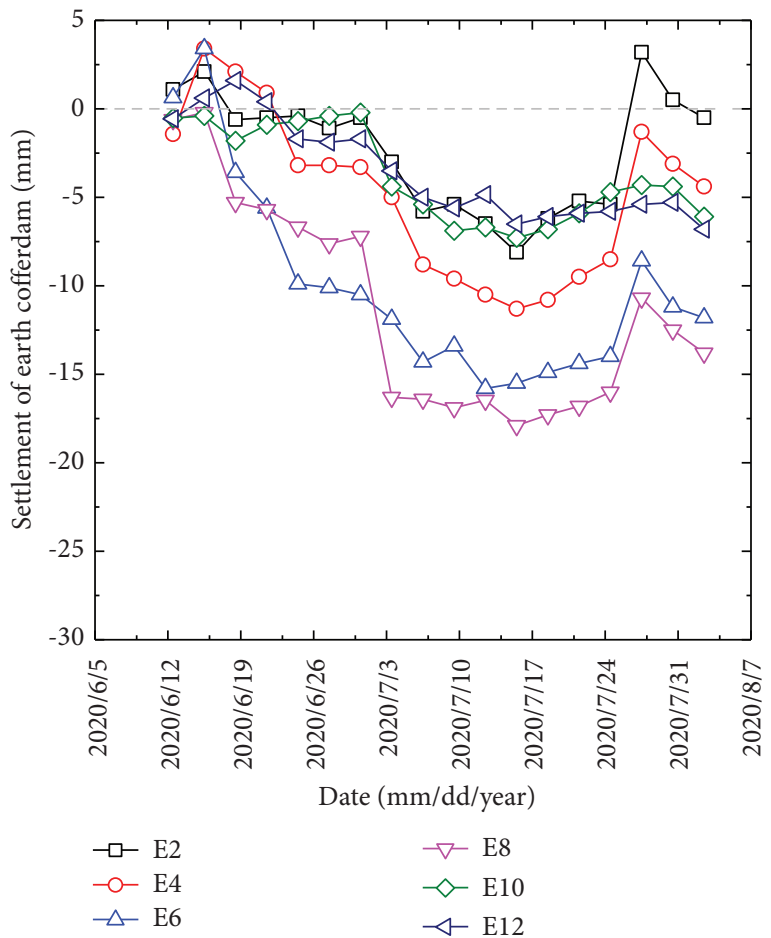

(b)

Figure 19: Variation of the measured ground settlements of the earth cofferdam with time. (a) Upstream side and (b) excavation side.

to the literature $[9,10,18]$. The parameters of each layer used in the numerical model are shown in Table 2. The constitutive parameters of the retaining structures are shown in Table 3.

6.2. Lateral Soil Movement. Figure 21(a) displays a comparison of the vertical movement of the DSSPs between the
FEM and the measurements. It is found that the numerical results have a similar tendency to those of the measurements. The difference between the FEM and the measurements is in the range of $10.02 \%-45.01 \%$, which validates the correctness of the numerical model. The distribution of lateral soil movement of the foundation pit at Stage 3(a) is shown in Figure 21(b). It is clearly seen that the value of lateral soil movement reaches $2.87 \mathrm{~cm}$, which appears in the mucky silty clay. 


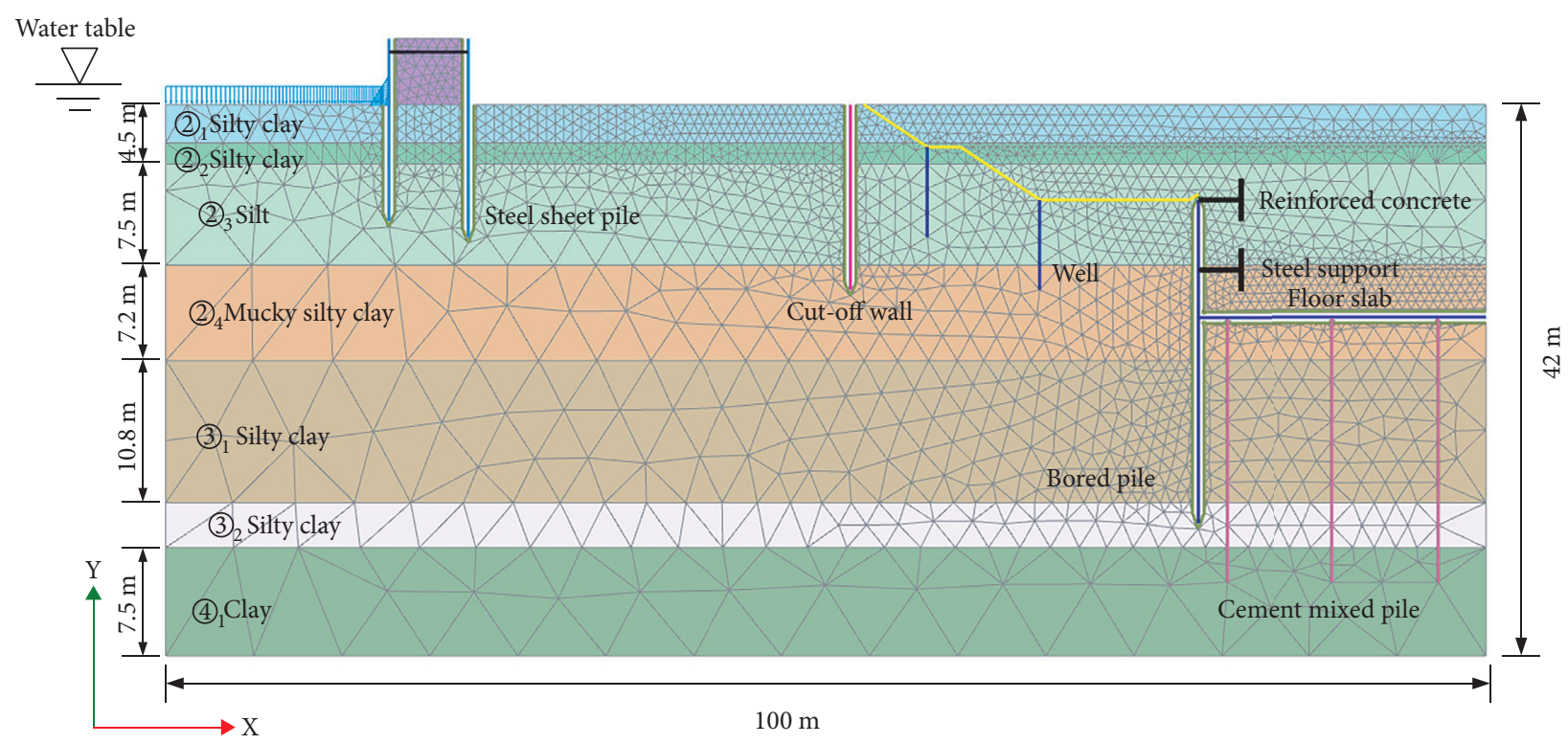

Figure 20: Two-dimensional finite element model and mesh generation.

TABLE 2: Summary of main geotechnical properties of soil layers.

\begin{tabular}{|c|c|c|c|c|c|c|c|}
\hline Soil layer & $\gamma_{\text {unsat }}\left(\mathrm{kN} / \mathrm{m}^{3}\right)$ & $\gamma_{\mathrm{sat}}\left(\mathrm{kN} / \mathrm{m}^{3}\right)$ & $E_{\mathrm{s}}\left(\mathrm{kN} / \mathrm{m}^{2}\right)$ & $v$ & $c(\mathrm{kPa})$ & $\varphi\left({ }^{\circ}\right)$ & $k(\mathrm{~cm} / \mathrm{s})$ \\
\hline (2) 1 Silty clay & 16.8 & 19.4 & 20000 & 0.31 & 34.4 & 34.7 & $4.39 E-06$ \\
\hline (2) 2 Silty clay & 17.7 & 18.9 & 20000 & 0.31 & 22.6 & 12.2 & $1.08 E-05$ \\
\hline (2) 3 Silt & 18.1 & 19.1 & 30000 & 0.30 & 12.6 & 26.5 & $1.79 E-04$ \\
\hline (2) 4 Mucky silty clay & 16.7 & 17.8 & 10000 & 0.35 & 13.7 & 5.3 & $7.35 E-06$ \\
\hline (3) Silty clay & 18.9 & 19.7 & 23000 & 0.33 & 36.2 & 14.2 & $3.77 E-06$ \\
\hline (3) 2 Silty clay & 17.3 & 18.2 & 23000 & 0.33 & 19.0 & 13.0 & $1.78 E-06$ \\
\hline (4) 1 Clay & 18.5 & 19.5 & 35000 & 0.35 & 46.6 & 14.7 & $8.27 E-07$ \\
\hline Cohesive soil & 18.5 & 19.5 & 35000 & 0.35 & 45 & 15 & $1.0 E-07$ \\
\hline
\end{tabular}

Note: $\gamma_{\text {unsat }}=$ unsaturated unit weight; $\gamma_{\text {sat }}=$ saturated unit weight; $E_{\mathrm{s}}=$ Young's ground modulus; $v=$ Poisson's ration; $c=$ cohesion; $\varphi=$ friction angle; $k=$ permeability.

TABle 3: Constitutive parameters of retaining structures.

\begin{tabular}{|c|c|c|c|c|}
\hline Structure type & $\mathrm{EA}(\mathrm{kN} / \mathrm{m})$ & EI $\left(\mathrm{kN} \mathrm{m}^{2} / \mathrm{m}\right)$ & $v$ & $W\left(\mathrm{kN} / \mathrm{m}^{2}\right)$ \\
\hline Steel sheet piles & $4.8 \times 10^{7}$ & $2.5 \times 10^{5}$ & 0.25 & 20 \\
\hline Bored piles & $7.5 \times 10^{6}$ & $4.0 \times 10^{5}$ & 0.2 & 24 \\
\hline Cut-off walls & $6.5 \times 10^{6}$ & $5.5 \times 10^{5}$ & 0.2 & 24 \\
\hline Cement mixed piles & $7.0 \times 10^{6}$ & - & - & 24 \\
\hline Steel strut & $2.0 \times 10^{7}$ & - & - & - \\
\hline Reinforced concrete & $3.5 \times 10^{7}$ & - & - & - \\
\hline Floor slab & $6.0 \times 10^{6}$ & $4.0 \times 10^{4}$ & 0.2 & 24 \\
\hline
\end{tabular}

Note: EA = axial stiffness; EI = bending stiffness; $W=$ weight; $v=$ Poisson's ratio.

6.3. Effect of Seepage Force. A hypothetical numerical case was examined to reveal the effect of groundwater on the deformation of bored piles. In the hypothetical case, the pumping wells were neglected so that the groundwater was assumed to be undrained in the soil layers. Figure 22 shows a comparison of the pile deformations between the actual case and the hypothetical case. The maximum deflection of the bored piles in the actual case is $2.12 \mathrm{~cm}$, while that of the bored piles affected by groundwater is $4.11 \mathrm{~cm}$. Using the strength reduction method, the safety coefficients of the foundation pit for the two cases are 1.61 and 1.39. Therefore, the seepage force leads to the large pile deflection and the low foundation pit stability. 


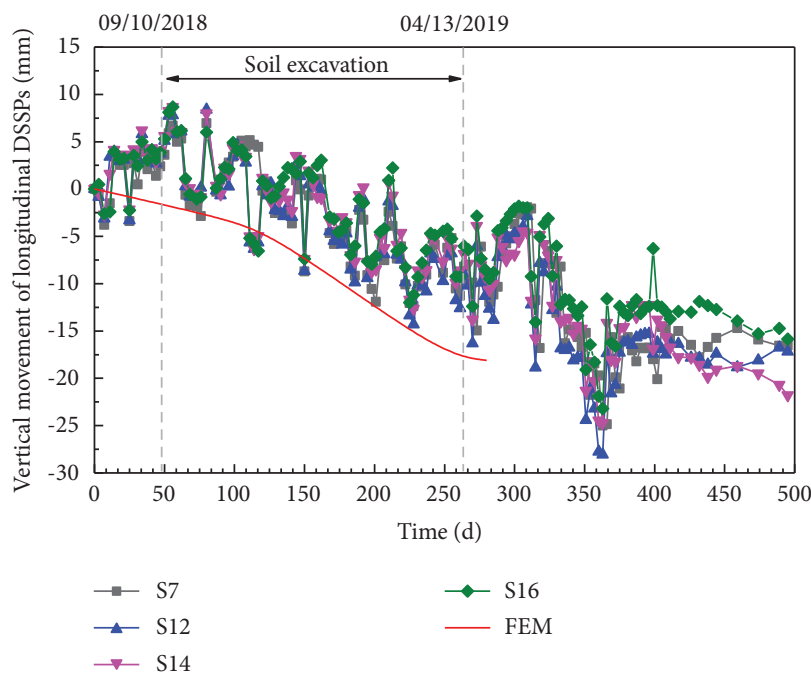

(a)

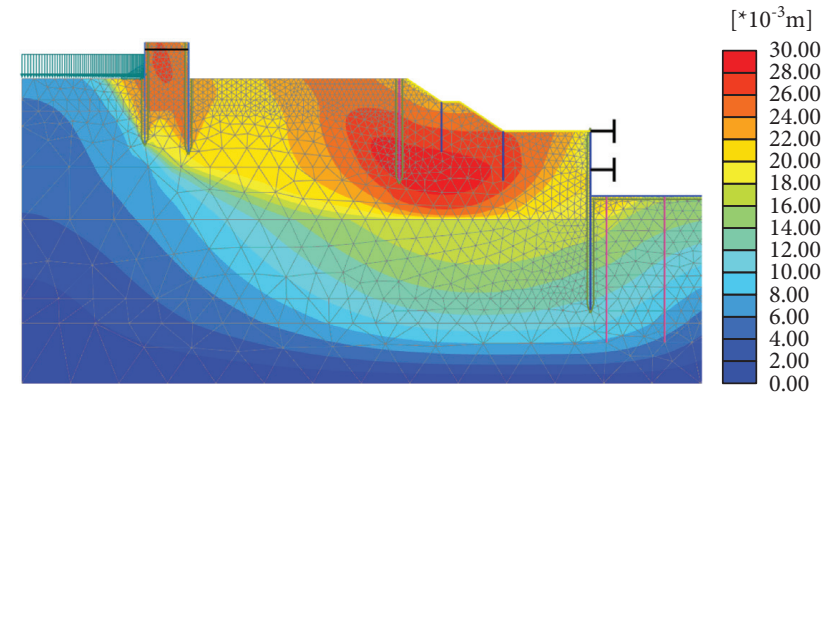

(b)

FIGURE 21: (a) Comparison of the vertical movements of DSSPs between FEM and measurements and (b) lateral soil movements of the foundation pit at Stage 3(a) calculated with the FEM.

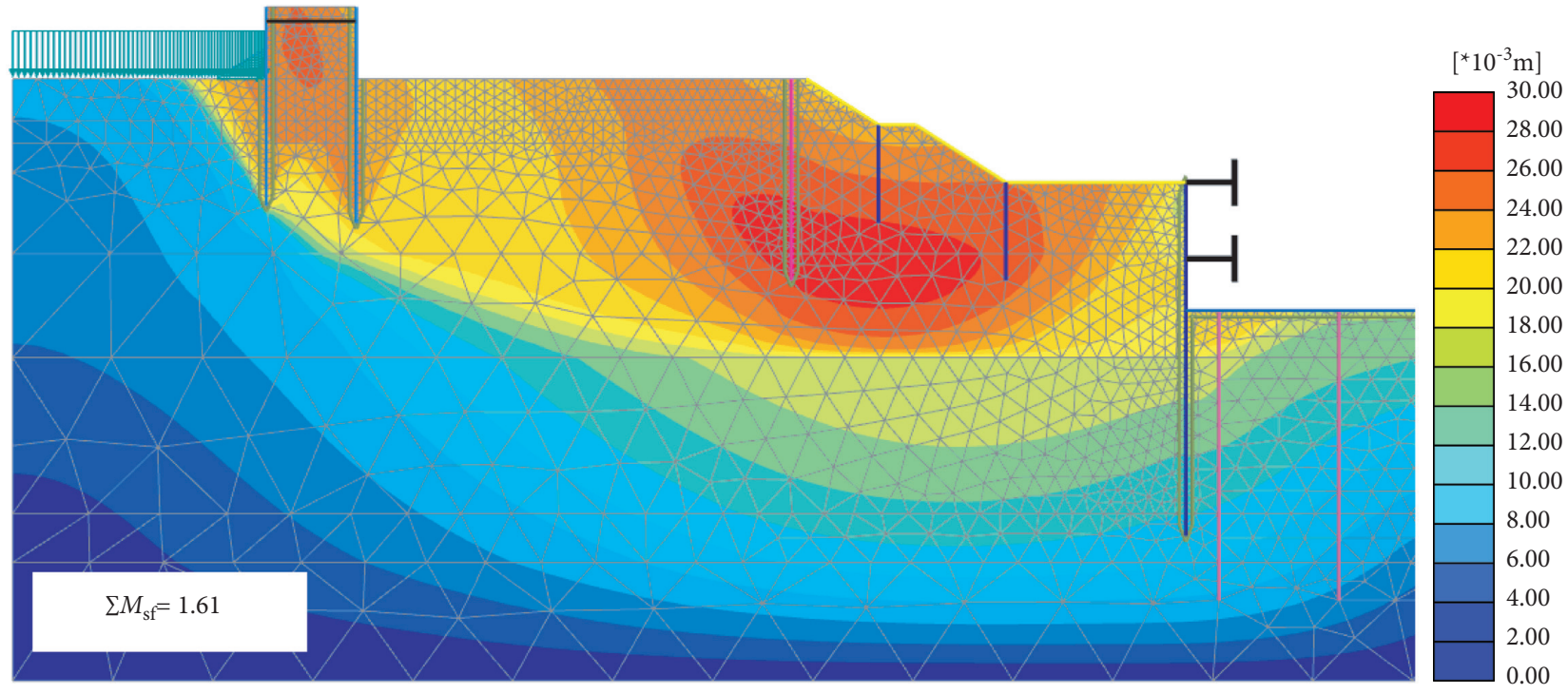

(a)

Figure 22: Continued. 


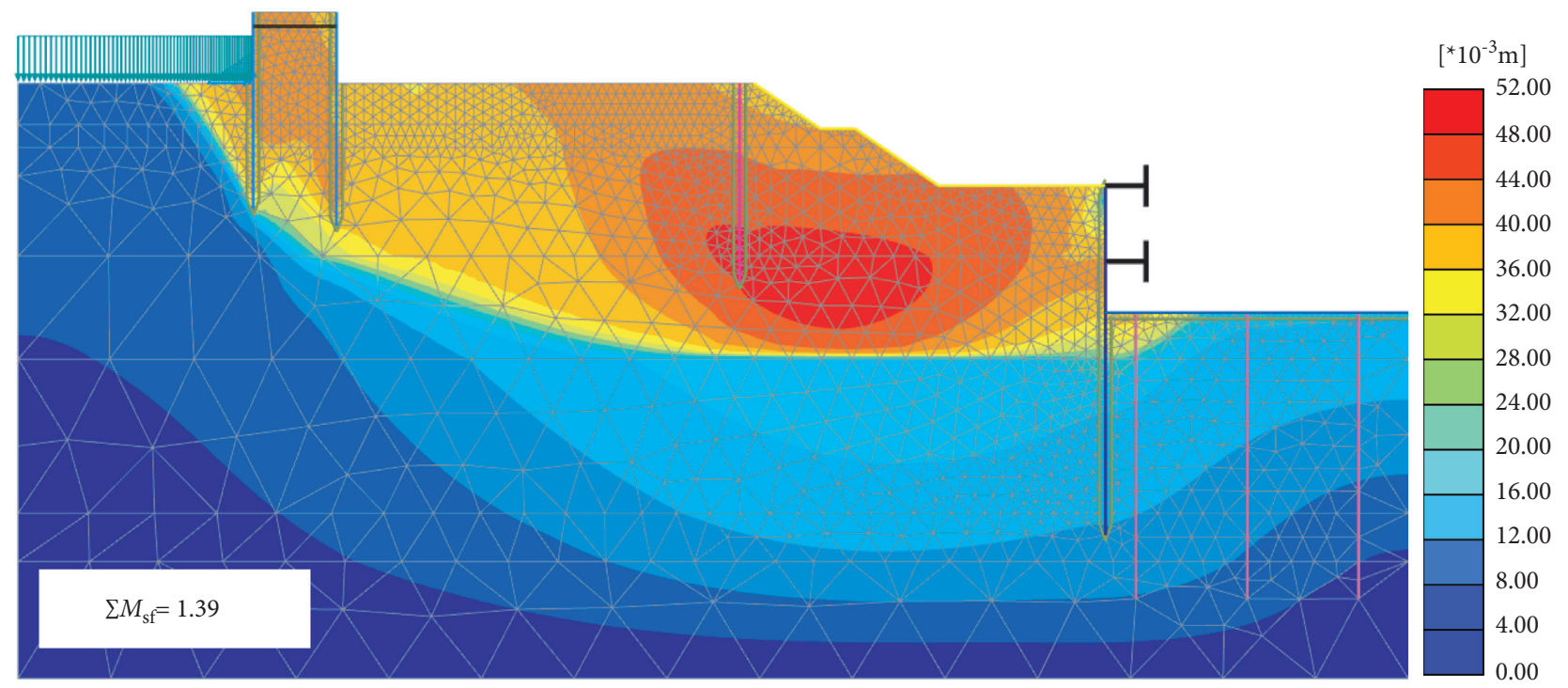

(b)

FIgURE 22: Effect of seepage force on the deformation of piles. (a) Actual numerical case and (b) hypothetical numerical case.

\section{Conclusions}

This paper presents a novel excavation and construction method for the Taihu tunnel, which is the longest lakecrossing tunnel in China. In the new method, an assembly line for the tunnel excavation was established to accelerate the construction speed, and the excavation did not cut off the normal flow of the lake water and the shipping routes. To investigate the tunnel deformation, a finite element analysis combined with field monitoring data was adopted. The following conclusions can be drawn:

(1) The DSSPs experienced settlements in the vertical direction and movements toward the excavation side in the horizontal direction. The maximum vertical and horizontal movements were $28.05 \mathrm{~mm}$ and $-39.53 \mathrm{~mm}$, respectively. In addition, the magnitudes of the deformations of the transverse DSSPs were smaller than those of the longitudinal DSSP. Three factors might have contributed to such deformations: (1) the hydrostatic pressure of lake water, (2) wave action, and (3) soil excavation.

(2) The maximum lateral deflections of the bored piles along excavation depth were between $\delta_{h m}=0.006 \% H_{\mathrm{e}}$ and $\delta_{h m}=0.06 \% H_{\mathrm{e}}$. However, the values of $\delta_{h m}$ were significantly smaller than the measurements reported by Clough and O'Rourke [21] for excavations in stiff clay, by Hashash et al. [22] for excavations in soft-to-medium clay, and by Tan and Wei [6] for excavations in soft Shanghai clay. The extensive use of underground structures, such as cut-off walls and cement mixed piles, the rapid cast of floor slabs, and the quick construction of bored piles might have contributed to this phenomenon.
(3) The bored piles unexpectedly experienced heaves instead of settlements, and the maximum vertical movement at the top of bored piles was approximately $21.51 \mathrm{~mm}$ along B4 on the north side of the foundation pit. The elastic and plastic rebound of soils at the bottom of the foundation pit and the soil movements around the bored piles might have contributed to such upward movements [6].

(4) The ground settlements increased with time during the excavation and then tended to be stable after the construction of floor slabs. Therefore, the casting of floor slabs and the construction of tunnel ancillary structures stabilized the retaining structures and surrounding soils. The upper and lower boundaries of the maximum ground settlements at each excavation depth were bounded by $\delta_{\mathrm{vm}}=0.01 \% H_{\mathrm{e}}$ and $\delta_{\mathrm{vm}}=0.1 \% H_{\mathrm{e}}$, which were lower than those reported in the literature $[6,21,22]$. Finally, the settlements of the earth cofferdam, which was located between WSS and Zone \#1, were shown in this study.

(5) To compare the field performance for revealing the greater impact of the tunnel excavation, a plainstrain numerical model was established based on the Mohr-Coulomb failure criterion. Two numerical cases were performed to study the effect of groundwater on the deformation of the piles, showing that the seepage force led to large pile deflection. Based on the strength reduction method, the safety coefficient of the foundation pit was 1.61, satisfying the safety requirement during tunnel excavation. The finite element analysis combined with field monitoring data reveals that the excavation and construction method could effectively control the tunnel deformations and enhance the overall stability. 


\section{Data Availability}

The data used to support the findings of this study are available from the corresponding author upon request.

\section{Conflicts of Interest}

The authors declare that there are no conflicts of interest regarding the publication of this study.

\section{Acknowledgments}

The authors gratefully acknowledge the financial support provided by the Major Research Program of the National Natural Science Foundation of China (grant no. 91747204) and the Project of the Jiangsu Provincial Transportation Engineering Construction Bureau (grant no. 818100116).

\section{References}

[1] C. Shi, C. Cao, and M. Lei, "Construction technology for a shallow-buried underwater interchange tunnel with a large span," Tunnelling and Underground Space Technology, vol. 70, pp. 317-329, 2017.

[2] M. Alp and A. Apaydin, "Assessment of the factors affecting the advance rate of the Tunnel Gerede, the longest and one of the most problematic water transmission tunnels of Turkey," Tunnelling and Underground Space Technology, vol. 89, pp. 157-169, 2019.

[3] Z.-N. Hu, Y.-L. Xie, and J. Wang, "Challenges and strategies involved in designing and constructing a $6 \mathrm{~km}$ immersed tunnel: a case study of the Hong Kong-Zhuhai-Macao Bridge," Tunnelling and Underground Space Technology, vol. 50, pp. 171-177, 2015.

[4] Y. Miao, X. Li, L. Kong, D. Wu, X. Chen, and J. Sun, "Study on the symmetric bilinear initiating technique of deep-hole boulder blasting in the TBM tunnel excavation," Tunnelling and Underground Space Technology, vol. 111, Article ID 103871, 2021.

[5] X. Xiao, J.-J. Chen, M.-G. Li, and J. H. Wang, "Field nonitoring of an existing cut-and-cover tunnel between two largescale deep excavations," Journal of Aerospace Engineering, vol. 31, no. 6, Article ID 04018082, 2018.

[6] Y. Tan and B. Wei, "Observed behaviors of a long and deep excavation constructed by cut-and-cover technique in Shanghai soft clay," Journal of Geotechnical and Geoenvironmental Engineering, vol. 138, no. 1, pp. 69-88, 2012.

[7] C. Lou, T. Xia, N. Liu, and X. Gong, "Investigation of threedimensional deformation behavior due to long and large excavation in soft clays," Advances in Civil Engineering, vol. 2019, Article ID 4187417, 12 pages, 2019.

[8] C. Cao, C. Shi, L. Liu et al., "Novel excavation and construction method for a deep shaft excavation in ultrathick aquifers," Advances in Civil Engineering, vol. 2019, Article ID 1827479, 15 pages, 2019.

[9] D. E. L. Ong, C. F. Leung, Y. K. Chow, and T. G. Ng, "Severe damage of a pile group due to slope failure," Journal of Geotechnical and Geoenvironmental Engineering, vol. 141, no. 5, Article ID 04015014, 2015.

[10] X. Cui, M. Ye, and Y. Zhuang, "Performance of a foundation pit supported by bored piles and steel struts: a case study," Soils and Foundations, vol. 58, no. 4, pp. 1016-1027, 2018.
[11] E. E.-M. Chong and D. E.-L. Ong, "Data-Driven field observational method of a contiguous bored pile wall system affected by accidental groundwater drawdown," Geosciences, vol. 10, no. 7, p. 268, 2020.

[12] J.-j. Zhou, J.-1. Yu, X.-n. Gong, and T.-l. Yan, "Field tests on behavior of pre-bored grouted planted pile and bored pile embedded in deep soft clay," Soils and Foundations, vol. 60, no. 2, pp. 551-561, 2020.

[13] M.-G. Li, Z.-J. Zhang, J.-J. Chen, J.-H. Wang, and A.-J. Xu, "Zoned and staged construction of an underground complex in Shanghai soft clay," Tunnelling and Underground Space Technology, vol. 67, pp. 187-200, 2017.

[14] D. Li and C. Yan, "Building deformation prediction based on ground surface settlements of metro-station deep excavation," Advances in Civil Engineering, vol. 2018, Article ID 6050353, 11 pages, 2018

[15] J.-J. Chen, Y.-F. Zhu, M.-G. Li, and S. L. Wen, "Novel excavation and construction method of an underground highway tunnel above operating metro tunnels," Journal of Aerospace Engineering, vol. 28, no. 6, Article ID A4014003, 2015.

[16] M. N. Houhou, F. Emeriault, and A. Belounar, "Three-dimensional numerical back-analysis of a monitored deep excavation retained by strutted diaphragm walls," Tunnelling and Underground Space Technology, vol. 83, pp. 153-164, 2019.

[17] P.-G. Hsieh, C.-Y. Ou, and Y.-L. Lin, "Three-dimensional numerical analysis of deep excavations with cross walls," Acta Geotechnica, vol. 8, no. 1, pp. 33-48, 2013.

[18] H. Liu, K. Li, J. Wang, and C. Cheng, "Numerical simulation of deep foundation pit construction under complex site conditions," Advances in Civil Engineering, vol. 2021, Article ID 6669466, 11 pages, 2021.

[19] W. An, L. Duan, Y. Zhang et al., "Occurrence, spatiotemporal distribution, seasonal and annual variation, and source apportionment of poly- and perfluoroalkyl substances (PFASs) in the northwest of Tai Lake Basin, China," Journal of Hazardous Materials, vol. 416, Article ID 125784, 2021.

[20] inMinistry of Water Resources of the People's Republic of China (MWRC). Specification of Soil Test (SL237-1999)China Water Power Press, Beijing, China, 1999, in Chinese.

[21] G. W. Clough and T. D. O'Rourke, "Construction induced movements of in-situ walls," in Design and Performance of Earth Retaining Structures, pp. 439-470, ASCE, Reston, VA, USA, 1990.

[22] Y. M. A. Hashash, A. Osouli, and C. Marulanda, "Central artery/tunnel project excavation induced ground deformations," Journal of Geotechnical and Geoenvironmental Engineering, vol. 134, no. 9, pp. 1399-1406, 2008.

[23] G. W. Clough, E. M. Smith, and B. P. Sweeney, "Movement control of excavation support systems by iterative design," Proc., Foundation engineering: Current Principles and Practices, vol. 2, pp. 869-884, 1989.

[24] K. Terzaghi, Theoretical Soil Mechanics, Wiley, New York, 1943.

[25] Z. W. Wang, C. W. Ng, and G. B. Liu, "Characteristics of wall deflections and ground surface settlements in Shanghai," Canadian Geotechnical Journal, vol. 42, no. 5, pp. 1243-1254, 2005.

[26] J. H. Wang, Z. H. Xu, and W. D. Wang, "Wall and ground movements due to deep excavations in Shanghai soft soils," Journal of Geotechnical and Geoenvironmental Engineering, vol. 136, no. 7, pp. 985-994, 2010. 